
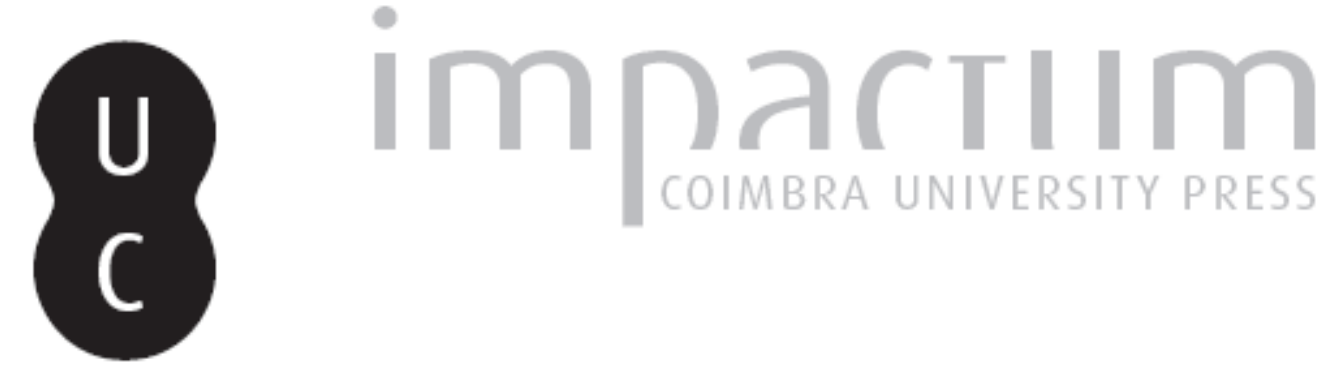

\title{
Benefícios fiscais ou transferências diretas para o terceiro setor?: a elasticidade- preço dos donativos empresariais
}

Autor(es): $\quad$ Taborda, Daniel; Martins, António

Publicado por: Faculdade de Direito da Universidade de Coimbra

URL persistente:

URI:http://hdl.handle.net/10316.2/30703

DOI:

DOI:http://dx.doi.org/10.14195/0870-4260_55_3

Accessed : $\quad$ 26-Apr-2023 12:14:11

A navegação consulta e descarregamento dos títulos inseridos nas Bibliotecas Digitais UC Digitalis, UC Pombalina e UC Impactum, pressupõem a aceitação plena e sem reservas dos Termos e Condições de Uso destas Bibliotecas Digitais, disponíveis em https://digitalis.uc.pt/pt-pt/termos.

Conforme exposto nos referidos Termos e Condições de Uso, o descarregamento de títulos de acesso restrito requer uma licença válida de autorização devendo o utilizador aceder ao(s) documento(s) a partir de um endereço de IP da instituição detentora da supramencionada licença.

Ao utilizador é apenas permitido o descarregamento para uso pessoal, pelo que o emprego do(s) título(s) descarregado(s) para outro fim, designadamente comercial, carece de autorização do respetivo autor ou editor da obra.

Na medida em que todas as obras da UC Digitalis se encontram protegidas pelo Código do Direito de Autor e Direitos Conexos e demais legislação aplicável, toda a cópia, parcial ou total, deste documento, nos casos em que é legalmente admitida, deverá conter ou fazer-se acompanhar por este aviso.

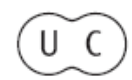


VOLUME LV

$\begin{array}{llll}2 & 0 & 1 & 2\end{array}$

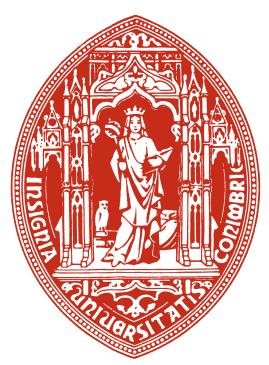




\section{BENEFÍCIOS FISCAIS OU TRANSFERÊNCIAS DIRETAS PARA O TERCEIRO SETOR? A ELASTICIDADE-PREÇO DOS DONATIVOS EMPRESARIAIS}

\section{Introdução}

A filantropia empresarial constitui um tema muito debatido na literatura internacional. Com efeito, a compreensão dos fatores que estão na origem da concessão de donativos pelas empresas, a forma mais comum de concretizar a filantropia e uma dimensão importante da responsabilidade social, tem despertado o interesse de muitos investigadores ${ }^{1}$. Porém, apesar da ideia generalizada de que todos os setores devem participar na prossecução do bem-estar geral, em Portugal, o tema da filantropia empresarial não tem tido a atenção que desperta noutras paragens.

O Estado partilha as suas responsabilidades com outros agentes económicos. $\mathrm{O}$ terceiro setor, previsto na Constituição

\footnotetext{
${ }^{1}$ No modelo de Carroll (1979), o último nível da "pirâmide da responsabilidade social" é ocupado pela filantropia. Para CAMPBELl ET AL. (2002), perspetivar a concessão de donativos como a expressão de uma atitude socialmente responsável, sem olvidar a natureza mais lata desta última, relaciona-se com a sua facilidade de mensuração, o que explica a sua popularidade na literatura.
} 
da República Portuguesa (CRP) ${ }^{2}$, complementa o papel do setor público na satisfação das necessidades coletivas. As iniciativas do terceiro setor tornam-se ainda mais importantes num quadro de graves constrangimentos orçamentais. O setor privado não lucrativo organiza-se de uma forma flexível, dinâmica e aberta à participação dos cidadãos, transmitindo-lhes um sentimento de utilidade, reforçando a solidariedade e a coesão social. Funciona, ainda, sob uma lógica de proximidade com os beneficiários, tendo consciência das suas necessidades e acompanhando de perto a sua evolução.

O Estado reconhece estas virtualidades e apoia o crescimento e a consolidação do terceiro setor. Fá-lo através de transferências diretas ou da consagração de beneficios fiscais aos agentes privados que lhe concedem donativos, abdicando da receita fiscal inerente (transferências indiretas) ${ }^{3}$. As entidades beneficiárias consagradas no regime do mecenato têm formas diversas. A delimitação genérica e imprecisa do terceiro sector (“o que não é público nem privado lucrativo") jus-

${ }^{2}$ Fernandes Ferreira (2005:250) sustenta que o art. 82. ${ }^{\circ}$, n. ${ }^{\circ}$ 4, da CRP abre o terceiro sector às "cooperativas, comunidades locais, explorações coletivas por trabalhadores, pessoas coletivas sem carácter lucrativo que tenham como principal objetivo a solidariedade social, designadamente entidades de natureza mutualista; a Constituição não designa expressamente mais instituições, mas entende-se que sejam as fundações e as associações". Observa que "em harmonia com a lei portuguesa, as instituições ditas do terceiro sector serão as que não pertencem nem ao sector público nem ao sector privado, mas este último tomado, aqui e agora, em conformidade com o "sector empresarial e não cooperativo» (empresas individuais, sociedades civis e comerciais e grupos de sociedades)".

${ }^{3} \mathrm{O}$ regime fiscal dos donativos espraia-se pelo capítulo $\mathrm{X}$ do EBF (passou a integrar o Estatuto do Mecenato, previsto no revogado Decreto-Lei n. ${ }^{\circ}$ 74/99, de 16 de Março, tendo-se conservado o seu conteúdo essencial), pelo Estatuto do Mecenato Científico (Lei n. ${ }^{\circ}$ 26/2004, de 8 de Julho) e por legislação avulsa (tendencialmente mais rara, o que é de aplaudir). Doravante, este quadro normativo designar-se-á por regime do mecenato. 
tifica que o regime do mecenato proceda a uma enumeração detalhada dos beneficiários, que, de resto, incluem também entidades do setor público. Independentemente da sua natureza pública ou privada, as entidades recipientes de donativos mecenáticos têm de prosseguir determinadas atividades consideradas relevantes nas áreas social, cultural, ambiental, desportiva, educacional ou científica, e de estar tipificadas na lei. O art. 62. ${ }^{\circ}$ do Estatuto dos Benefícios Fiscais (EBF) estratifica o "interesse público" das instituições recipientes e das atividades apoiadas através da consagração de limites à dedutibilidade dos donativos (fixados em permilagem do volume de vendas) e da aplicação de majorações.

A análise comparativa das transferências diretas para o terceiro setor com o seu financiamento indireto, através do reconhecimento de benefícios fiscais às empresas mecenas, constitui o objetivo central deste trabalho. Para isso, divide-se em três partes. Na primeira, apresentam-se as variáveis que, segundo a literatura da especialidade, influenciam a atribuição de donativos. Na segunda, com base numa amostra de dados de empresas portuguesas, propõe-se a estimação da elasticidade-preço dos donativos e, na terceira, evidenciam-se as principais conclusões e limitações deste trabalho.

\section{As Variáveis Explicativas dos Donativos Empresa- riais: uma revisão da literatura}

As variáveis empresariais que condicionam os donativos, e que apresentam maior predomínio na literatura, são: o nível de endividamento, os custos com publicidade, a performance económico-financeira, a dimensão, as características do setor e a taxa de imposto. De seguida, descreve-se a sua mensuração e, bem assim, a relação que existe em cada uma delas e a atribuição de donativos pelas entidades empresariais. 


\subsection{Nível de endividamento}

Uma empresa endividada tem obrigações financeiras acrescidas e, paralelamente, incorre em custos de natureza diversa (decorrentes, por exemplo, da imposição de garantias contratuais e do aumento do risco de falência). Os contratos de crédito podem acarretar problemas de solvência, auditorias não previstas, limitações ao investimento e dificuldades na obtenção de fontes adicionais de financiamento (ADAMS e HARDwick, 1998). Em situações de sobre-endividamento, assiste-se a uma maior pressão exercida por alguns agentes interessados (stakeholders) sobre os órgãos de gestão, no sentido da diminuição da dívida (Brammer e Millington, 2004, Brown et al., 2006). Ou seja, o nível de vigilância sobre a empresa aumenta, limitando a liberdade dos gestores.

DunN (2004) salienta que muitos contratos de financiamento estabelecem limites para o nível de despesas.Acrescenta que se as restrições impostas pelos credores - que, entre outras, englobam a moderação na distribuição de dividendos e a manutenção da titularidade do capital - estiverem na iminência de ser ultrapassadas, a filantropia é das primeiras atividades a ser dispensada (a redução do nível de donativos traduz-se no aumento do resultado líquido e, por esta via, na melhoria da solvabilidade).

Quanto maior é o nível de endividamento, mais recursos são adstritos ao cumprimento do serviço da dívida, reduzindo a possibilidade de empreender projetos destinados ao aumento da responsabilidade social da organização (Graves e Waddock, 1994, Choi e Jung, 2008). Frequentemente, os donativos são vistos como despesas não diretamente relacionadas com a atividade empresarial, o que, conjugado com a dificuldade de mensuração dos seus benefícios, suscita diversas críticas. Daí que, em condições financeiras restritivas, os gestores tendam a canalizar os fundos disponíveis para atividades que permitam obter resultados para a empresa. 
$\mathrm{Na}$ literatura relativa à teoria da agência, no tocante aos conflitos entre gestores e proprietários, argumenta-se que o endividamento evita uma afetação de fundos menos eficiente, comprimindo a margem de atuação dos gestores e, portanto, as opções de maximização da sua utilidade. De facto, um nível de endividamento elevado tem repercussões na subida do prémio de risco exigido pelos financiadores e, consequentemente, gera maior despesa com os empréstimos contraídos. Assim, os constrangimentos impostos pela estrutura de capital requerem uma gestão mais disciplinada e rigorosa, com efeitos na redução dos donativos atribuídos.

Por outro lado, do estrito ponto de vista da gestão fiscal, os donativos e o recurso a capital alheio constituem fontes de proteção fiscal ${ }^{4}$. Esta abordagem destaca a substituibilidade fiscal destas duas variáveis, reforçando a sua relação negativa.

Um indicador muito comum na escola anglo-saxónica, que mede o peso do capital alheio no financiamento das atividades da empresa, é o chamado indicador de alavancagem (Leverage). A relação entre o passivo e os capitais próprios foi a fórmula utilizada por Navarro (1988a) e BoAtsman e Gupta (1996) no estudo dos donativos empresariais. Assim, é esperável que, coeteris paribus, as organizações com um elevado nível de Leverage concedam menos donativos.

${ }^{4} \mathrm{O}$ estudo pioneiro de Modigliani e Miller (1958) concluiu pela independência do valor da empresa face à respetiva estrutura financeira. Mais tarde, em 1963, estes autores, introduzindo a variável fiscal no seu modelo, demonstraram as vantagens do recurso ao endividamento, comparativamente ao financiamento por capitais próprios, por força de os encargos associados ao capital alheio serem dedutíveis. Simplificadamente, a procura de uma estrutura de capital ótima centra-se na minimização da probabilidade de falência e na maximização dos efeitos fiscais inerentes ao custo da dívida. 


\subsection{Custos com publicidade}

A filantropia organizacional pode funcionar como um instrumento de melhoria da imagem da empresa, facilitando as relações com as autoridades, atraindo a atenção da comunicação social e servindo de suporte a campanhas de marketing (Fry et al., 1982, Clotfelter, 1985, Navarro, 1988a, Boatsman e Gupta, 1996, Galaskiewicz, 1997, Bennett, 1998).

Para GARDBERG e FOMBRUn (2006), a filantropia insere-se numa estratégia de diferenciação, complementando as despesas de I\&D e de publicidade. Por isto, é razoável admitir que as empresas com grande orientação para o cliente, com o propósito de aumentarem a notoriedade das marcas dos seus produtos, concedem mais donativos. Todavia, tendo presente a importância do capital reputacional da organização, a concessão de donativos poderá funcionar como uma forma de estreitamento das relações com os outros stakeholders, que não apenas os clientes 5 .

Os resultados empíricos de alguns estudos sugerem que existe uma relação positiva entre donativos e custos com publicidade (Levy e Shatto, 1978, Cain e Cain, 1985, Fry et al., 1982, Carroll e Joulfaian, 2005, Brown et al., 2006, Амato e Амato, 2007, Brammer et al., 2009).

De forma diversa e com fundamento na ausência de neutralidade fiscal, pode argumentar-se que, em vez de complementares, os custos com publicidade e os donativos são sucedâneos, o que conduz a uma relação negativa entre estas variáveis (Keim et al., 1980). Clotfelter (1985) nota que,

5 Porter e Kramer (2002:58) sustentam que a filantropia deve enquadrar-se nas competências centrais da organização e ser uma fonte de vantagens competitivas. Definem a "filantropia estratégica" como o conjunto de atividades "que têm um tema, abordagem, objetivo ou foco específicos". 
sobretudo na hipótese de a dedutibilidade dos donativos ser limitada (tal como se verifica na legislação portuguesa), as despesas com a publicidade poderão ser uma alternativa aos donativos, traduzindo uma alteração do seu preço relativo. Sem embargo, a generalidade da literatura milita a favor de uma relação direta entre os donativos e os custos com publicidade.

\subsection{Performance económico-financeiva}

O impacto da responsabilidade social na performance económico-financeira, amplamente estudado na literatura, tem originado resultados inconclusivos. Mais pacífica e consensual é a ideia de que as empresas com boa performance económico-financeira apresentam, tendencialmente, uma melhor performance social (BuchHoltz et al., 1999, Seifert et al., 2004). Tanto a teoria dos recursos escassos como a teoria da agência, sustentam, por razões diferentes, esta relação. À luz da primeira, as empresas mais lucrativas têm maior capacidade para realizar atividades sociais ${ }^{6}$. No âmbito da segunda, admite-se que a existência de fundos em excesso potencia comportamentos que aproveitam à utilidade dos gestores, nomeadamente o envolvimento em atividades filantrópicas.

As atividades sociais requerem recursos e, assim, é natural que o desempenho económico-financeiro tenha influência no "comportamento social" das organizações (Cochran e Wood, 1984, Mcguire et al., 1988, Schuler e Cording, 2006). Esta conclusão deriva diretamente da catalogação das responsabilidades sociais do modelo piramidal proposto por

${ }^{6}$ A maioria das empresas australianas, questionadas por SARGEANT e Crissman (2006) sobre as barreiras que a concessão de donativos enfrentava, invocou a escassez de recursos. 
Carroll (1979). Neste modelo, a filantropia surge como uma atividade adicional da organização, apenas exercida contanto não vulnerabilize a sua responsabilidade económica.

SEIFERT et al. (2003) comprovaram que o nível de recursos disponíveis numa organização tem um impacto positivo no montante de donativos concedidos, tal como Levy e Shatto (1978) e Carroll e Joulfaian (2005). Contudo, o montante de donativos não influencia a primeira variável. A neutralidade deste efeito contribui para o aumento das tensões entre duas teorias que postulam resultados diferentes. De acordo com a perspetiva mais instrumental da teoria dos stakeholders, a concessão de donativos pode promover a performance económico-financeira, através do fortalecimento das relações entre a organização e os seus constituintes. $\mathrm{O}$ compromisso comunitário favorece a conquista de novos mercados em ambientes estranhos e adequa o posicionamento estratégico da empresa: permite reunir informação relevante sobre a cultura e valores da comunidade e potencia uma expansão mais rápida, criando ativos intangíveis que melhoram a reputação da organização, com resultados profícuos ao nível da legitimação social e do reforço das relações institucionais (MARX, 1998, Gardberg e Fombrun, 2006). Para a teoria da agência, a concessão de donativos traduz-se na subtração de recursos à organização, reduzindo o financiamento disponível para outros projetos (McWilliams e Siegel, 2001), pelo que se presume uma relação negativa com a performance económico-financeira.

Num trabalho posterior, SEIFERT et al. (2004) debruçaram-se sobre as relações entre having (recursos financeiros) e giving (donativos), assim como entre giving e getting (performance económico-financeira). A primeira relação revelou ser significativamente positiva, mas não se encontrou qualquer relação entre as duas últimas variáveis. Para estes autores, os recursos financeiros "ociosos" são candidatos ao financiamento de despesas discricionárias, tendo o dinheiro, por natureza, maior 
versatilidade de aplicação. Daqui se infere que a distribuição de dividendos terá uma relação negativa com os donativos.

BoATSMAN e Gupta (1996) utilizaram as variáveis "resultado antes de impostos" e "cash-flows" para medirem o nível de rendimento de uma empresa. Concluíram que existe uma relação significativamente positiva entre o rendimento e os donativos. Porém, a elasticidade é muito baixa (cerca de 0,1 ), o que revela que as variações do nível de rendimento do setor privado provocam alterações menos do que proporcionais nos donativos. Os resultados de Schwartz (1968) e de ArulampaLAM e STONEMAN (1995) também sugerem que há uma relação positiva inelástica entre o nível de rendimento e os donativos.

Clotfelter (1985) recorreu a várias medidas do nível de rendimento, designadamente ao cash-flow antes de impostos e ao resultado líquido antes e depois de impostos, e concluiu que nenhuma se destacara em termos de capacidade explicativa. Utilizando os resultados líquidos antes de impostos, Clotfelter obteve uma elasticidade de 0,54, inferior à de Navarro (1988a), que se cifrou em 0,85. Partindo da heterogeneidade dos sectores apoiados, Navarro (1988b) calculou as elasticidades de quatro categorias de contribuições empresariais (artes e cultura, educação e investigação, cívicas e saúde e bem-estar) e concluiu que, para além de semelhantes, são pouco elásticas em relação ao rendimento ${ }^{7}$. Tal sugere que as

${ }^{7}$ Esta conclusão resultou da utilização de um modelo logarítmico que o autor reputa de mais adequado. Recorrendo a um modelo linear, os resultados diferem: há divergências entre as elasticidades das várias contribuições (variam entre 0,24 e 0,82 ) e, ao nível agregado, a relação estimada é mais inelástica do que no modelo logarítmico $(0,56$ e 0,85 , respetivamente). No entanto, os seus modelos apenas contemplam uma variável explicativa. Refira-se ainda que, tal como nota BAckus (2009), não é comum que os estudos sobre os donativos categorizem esta variável por tipo de causa apoiada. Por regra, os donativos mecenáticos são tratados como uma realidade homogénea. 
entidades recipientes dos donativos estão expostas aos ciclos económicos, mas, coeteris paribus, a variação do nível de donativos é proporcionalmente inferior à do rendimento.

Face ao exposto, parece razoável a hipótese de que, coeteris paribus, empresas que têm uma boa performance económico-financeira atribuem mais donativos. No entanto, dado que a performance económico-financeira é um conceito multidimensional e de existir uma panóplia de variáveis contabilísticas e de mercado para a sua mensuração, algumas conclusões na literatura, sobretudo no tocante ao valor da elasticidade-rendimento, são ambíguas. Por regra, esta relação é inelástica, tal como mostram os resultados de Schwartz (1968), Clotfelter (1985), Navarro (1988a), Boatsman e Gupta (1996), Adams e Hardwick (1998) e Day e Devlin (2004).

\subsection{Dimensão}

Para Useem (1988:81), a dimensão é um dos fatores institucionais que mais influencia o montante de donativos: "empresas maiores contribuem com mais dinheiro, independentemente dos lucros". SARgeANT e CRISSMAN (2006) confirmaram que, no período 2003/2004, 89\% das grandes empresas australianas (mais de 501 funcionários), apesar de apenas representarem $1 \%$ do número total de empresas, foram responsáveis por $20 \%$ dos donativos.

A atuação das grandes empresas está mais sujeita ao escrutínio do público e do Estado, em virtude de reunirem mais stakeholders e de o seu grau de exposição pública ser maior. Parafraseando NAvarro (1988a:68), "na arena política, a concessão de donativos pode assumir-se como uma tática útil num contexto de uma estratégia geral de lobby delineada para criar ou manter um clima de negócio favorável”. De facto, boas relações com as entidades reguladoras podem resultar num 
maior nível de segurança de atuação das empresas e, inclusivamente, proporcionarem maiores possibilidades de participação no processo legislativo que as afeta.

Sob este ponto de vista, é compreensível que a concessão de donativos tenha como propósito a redução do risco de o Estado impor custos adicionais (maior nível de fiscalidade, nacionalização, expropriação, limitações de preços, acusação de práticas monopolistas, entre outras adversidades). GAN (2006) observou que o escrutínio do Estado, medido pelo nível de contencioso com a organização, tem efeitos significativos nos donativos, tendência que é amplificada pela cobertura da comunicação social. SAIIA et al. (2003) demonstraram que o grau de exposição pública, entendido como o nível de abertura e de vulnerabilidade da organização ao seu ambiente social, condiciona fortemente o alinhamento estratégico da filantropia.

Brammer e Millington (2006) afirmam que as organizações de grande dimensão dispõem de um poder económico e institucional que lhes permite determinar o seu grau de resposta social sem grandes constrangimentos. Além disto, as empresas maiores estão publicamente mais expostas, pelo que a sua reputação poderá ficar abalada se a sua performance social for deficiente. Têm naturalmente mais visibilidade, ficando sujeitas a maior regulação, ainda que implícita, por parte dos seus stakeholders, sobretudo pertencentes ao campo sociopolítico ${ }^{8}$. Adicionalmente, pela sua notoriedade, são o alvo preferencial dos fund-raisers.

${ }^{8}$ Refira-se, no entanto, que estes autores trataram a dimensão e o grau de visibilidade pública como duas variáveis independentes, o que não é comum na literatura, em virtude de estarem, normalmente, correlacionadas. 


\subsection{Características do setor}

Se a imagem pública é importante para qualquer organização, para as empresas cujas vendas sejam muito sensíveis às perceções do público, tal imagem assume uma expressão ainda mais vincada (Clotfelter, 1985). Arulampalam e Stoneman (1995) mostraram que se verifica uma relação positiva entre o grau de contacto com o público e o nível de donativos concedidos, sendo as mais generosas, coeteris paribus, instituições financeiras e retalhistas. Resultado similar foi encontrado por Fry et al. (1982). Em sentido diferente, o estudo de GALASKIEWICZ (1997), que distinguiu entre empresas mais ou menos dependentes da venda ao público, não obteve qualquer relação com o montante de donativos, tal como ADAMs e HARDWICK (1998).

Sob outra perspetiva, também Brammer e Millington (2004) advogam que o sector em que a organização opera tem influência na política de donativos. Os autores invocam a necessidade de compensação de externalidades negativas criadas pela empresa e, bem assim, a restritiva regulamentação a que está sujeita, para explicar a sua política filantrópica, ilustrando este argumento com os exemplos das chamadas "indústrias do pecado" (tabaco e álcool).

Todavia, colidindo com esta ideia, Palazzo e Richter (2005) referem que a filantropia, apesar do seu destaque nas ações de responsabilidade social, não é generalizável a todos os sectores. De acordo com o seu estudo, que teve por objeto o sector tabaqueiro, as vantagens da filantropia encontram limites intransponíveis nesta indústria: a perceção do público de que se trata de dinheiro proveniente de uma atividade perniciosa sob o ponto de vista social e a dificuldade em atribuir à política filantrópica uma natureza estratégica. Assim, recomendam às empresas mais suscetíveis ao escrutínio público e que, simultaneamente, oferecem bens e serviços geradores de 
externalidades negativas, a adoção de outro tipo de ações de responsabilidade social ${ }^{9}$.

Brammer e Millington (2003) observaram que as empresas que atuam num sector sujeito a pressões dos stakeholders tendem a conceder mais donativos. Esta perspetiva enquadra-se numa lógica segundo a qual os donativos são um instrumento que influencia os decisores políticos, consumidores e investidores, designadamente em sectores mais expostos às ingerências políticas e sociais. As empresas procuram uma "licença de funcionamento", ou seja, enveredando por uma lógica pragmática, identificam temas sociais que sejam relevantes para os seus stakeholders e apostam empenhadamente na sua promoção. É de salientar que esta opção, comum em indústrias muito regulamentadas, pode funcionar como um paliativo que se perpetua, ficando a epresa refém das críticas do público e de eventuais alterações no plano da regulação, em particular da introdução, ou do agravamento, da tributação do tipo pigouviano ${ }^{10}$.

Por fim, refira-se que o nível concorrencial num dado sector poderá estar relacionado com os donativos. JoHNSON

${ }^{9}$ Contrariamente a esta advertência, segundo Porter e Kramer (2002), a Philip Morris despendeu cerca de 100 milhões de dólares na publicitação dos 75 milhões de donativos que atribuíra em 1999.

${ }^{10}$ A tributação pigouviana ou corretiva visa interiorizar os custos das externalidades negativas resultantes da atuação dos agentes económicos. É um instrumento de penalização fiscal das atividades cujos danos sociais superam os benefícios. Constitui uma forma popular de concretizar o princípio do poluidor-pagador, incentivando comportamentos ambientalmente responsáveis e procurando garantir a equidade intergeracional (eco tributação ou green taxation). Por isto se diz que são impostos assumidamente distorcivos, indutores de comportamentos, mas que promovem a eficiência económica e social. Casalta Nabais (2008) defende que os tributos bilaterais (taxas) são mais apropriados à concretização do princípio do poluidor-pagador do que os unilaterais (impostos). Acrescenta que este princípio não é facilmente conciliável com o princípio da capacidade contributiva, o critério de medida estruturante do nosso sistema fiscal. 
(1966) aventa a hipótese de as empresas monopolistas exibirem publicamente a sua responsabilidade social, atribuindo donativos. No entanto, obteve uma relação empírica negativa entre o grau de concentração da indústria e o nível de donativos. Concluiu assim que, tanto as empresas monopolistas, como as que operam em sectores muito concorrenciais concedem poucos donativos. As primeiras dispõem de uma posição privilegiada e não têm qualquer incentivo para seguir este tipo de comportamento, e as segundas apenas sobrevivem se as empresas rivais também adotarem políticas filantrópicas.

Note-se, por fim, que a discussão em torno desta variável tem vindo a ser progressivamente abandonada pela literatura, admitindo-se que, por si só, não condiciona a atribuição de donativos.

\subsection{Taxa de imposto}

O estudo da filantropia empresarial desenvolveu-se tradicionalmente em torno de dois modelos distintos: o modelo da maximização do lucro e o modelo da maximização da utilidade do órgão de gestão. A relação entre a taxa efetiva de imposto e o montante de donativos tem funcionado como um indicador da adesão destes modelos à realidade (SCHWARTZ, 1968, Navarro, 1988a, Arumlapalam e Stoneman, 1995, Boatsman e Gupta, 1996, Adams e Hardwick, 1998).

No primeiro modelo, os donativos são vistos como um input comum, subordinados ao incremento das receitas, pelo que a variação da taxa de imposto não tem qualquer efeito no respetivo montante. No segundo, considera-se que os donativos, cuja atribuição é decidida pelos gestores, contribuem para a satisfação pessoal destes, nomeadamente através do prestígio social e do relacionamento com as elites políticas e económicas. Uma vez que não concorrem para a obtenção de rendimento, 
os donativos têm origem nos lucros residuais, isto é, aqueles que não são reivindicados pelos sócios.

Admitindo a dedutibilidade fiscal dos donativos, então o aumento da taxa de IRC conduz a uma diminuição da preferência pelo lucro, tornando a sua troca pela concessão de donativos, ou por outras despesas discricionárias, compensadora, reduzindo assim o ónus da tributação. Dito de outra forma, o preço relativo dos lucros discricionários face às despesas que financiam é alterado, porquanto os primeiros estão sujeitos a tributação, ao invés das segundas que são dedutíveis.

O modelo da maximização da utilidade do órgão de gestão decompõe o impacto do aumento da taxa de imposto no montante de donativos concedidos em dois efeitos de sinal contrário: o efeito rendimento e o efeito substituição. No âmbito do primeiro, dado que os lucros são a fonte de financiamento dos donativos, o aumento da taxa de IRC constitui um fator potencialmente conducente à sua redução (relação negativa).

O efeito substituição sustenta uma relação positiva entre a taxa de IRC e o montante de donativos. Segundo o modelo de Williamson, o efeito substituição é superior ao efeito rendimento, pelo que, verificada a condição de existir um nível suficiente de lucros que satisfaça as pretensões dos sócios, a relação entre a taxa de imposto e o montante de despesas afetas às preferências de consumo dos gestores (de que são exemplo os donativos) é positiva ${ }^{11}$.

${ }^{11}$ Williamson (1963) introduziu o conceito de "expense preference", cuja relevância assenta no facto de os gestores não serem indiferentes à natureza dos encargos suportados pela organização. Dos diversos encargos enumerados, destaca-se o financiamento de várias atividades discricionárias, que não representam uma remuneração direta dos gestores, mas contribuem para a sua satisfação pessoal. Os fundos discricionários resultam da diferença entre os lucros obtidos (antes de impostos) e o montante mínimo de lucros (depois de impostos) exigido pelos sócios. Assim, o aumento da 
À semelhança de Levy e Shatto (1978) e de Carroll e Joulfaian (2005), os resultados de Arulampalam e Stoneman (1995) confirmaram uma relação significativa positiva entre a taxa de imposto e os donativos, prevalecendo o efeito substituição sobre o efeito rendimento.

\section{O Tratamento Estatístico: modelos, dados e resul- tados}

\subsection{Considerações gerais sobre o método dos dados em painel}

Os dados em painel, ou dados seccionais temporais, decorrem de um conjunto de observações recolhidas sobre unidades seccionais para sucessivos períodos cronológicos. Trata-se, por definição, de informação tridimensional (variáveis, indivíduos e momentos temporais), combinando os modelos cross-section (estáticos) com modelos time-series (dinâmicos, mas que se referem apenas a um indivíduo). Uma vez que nos foram disponibilizados dados de várias unidades seccionais (empresas), em sucessivos momentos temporais (quatro exercícios), utilizaremos a estimação com dados em painel ${ }^{12}$.

taxa de imposto sobre os lucros tem dois efeitos: o efeito substituição, que é positivo, e o efeito rendimento que é negativo. $\mathrm{O}$ efeito global tende a ser positivo, porquanto o primeiro prevalece sobre o segundo. Este é o modelo baseado na maximização da utilidade dos gestores e, segundo Williamson (1963:14), "é nas grandes empresas que as manifestações do comportamento discricionário são importantes”.

${ }^{12}$ Esta metodologia foi desenvolvida por vários autores, e seguimos, em particular, Hsiao (1985), BALtAgi (1995), Greene (1997) e wOOLDRIDGE (2002, 2003). A aplicação dos modelos de painel ao tema em estudo foi feita também por Arulampalam e Stoneman (1995), Boatsman e Gupta (1996), Carroll e Joulfaian (2005), entre muitos outros. 
Construir um modelo econométrico encontra sempre como barreira a identificação de todas as variáveis independentes que influenciam a variável dependente. A omissão de variáveis, que poderão ser importantes na explicação da variável dependente, é um inconveniente que pode ser aligeirado pela utilização de modelos de painel, admitindo a existência de efeitos individuais não observáveis (aleatórios ou fixos). Nos modelos de regressão estimados pelo método dos mínimos quadrados, o termo de erro inclui os efeitos das variáveis eventualmente omitidas na parte determinística. Na metodologia dos dados em painel, a consideração das duas fontes comuns de heterogeneidade - seccional e temporal - minimiza os problemas associados à modelização, designadamente no que à simplificação da realidade diz respeito.

Esta compatibilização da heterogeneidade dos comportamentos individuais com as dinâmicas temporais conduz ao aumento do número de observações e do número de graus de liberdade, a estimativas econométricas mais completas e eficientes, diminuindo o enviesamento da estimação, à redução do risco de multicolinearidade (ao variarem em duas dimensões, a probabilidade de as variáveis independentes estarem correlacionadas é menor) e à atenuação do impacto das variáveis omissas (Figueiredo e Hill, 2003). Em suma, melhora o poder explicativo dos modelos.

Optámos neste texto por omitir a descrição das características dos três tipos de modelos com dados em painel - pooled, com efeitos fixos e com efeitos aleatórios - e, bem assim, as demonstrações matemáticas dos vários testes utilizados na escolha do modelo mais ajustado. O quadro 1 resume os testes que permitem selecionar o modelo mais adequado. Procura, tão-somente, contribuir para uma melhor compreensão dos resultados apresentados mais adiante, em particular no que toca à terminologia empregue. 
QuAdro 1 - Testes para a seleção do modelo mais apropriado

\begin{tabular}{|l|c|c|}
\hline \multicolumn{1}{|c|}{ Decisão } & \multicolumn{1}{|c|}{ Teste; Hipóteses } & Modelo \\
\hline Pooled vs Efeitos Fixos & F; H0 - homogeneidade na constante & $\begin{array}{c}\text { Rejeita-se H0 => } \\
\text { efeitos fixos }\end{array}$ \\
\hline $\begin{array}{l}\text { Pooled vs Efeitos Alea- } \\
\text { tórios }\end{array}$ & $\begin{array}{c}\text { LM - Breusch e Pagan; H0 - homo- } \\
\text { geneidade no termo de erro }\end{array}$ & $\begin{array}{c}\text { Rejeita-se H0 => } \\
\text { efeitos aleatórios }\end{array}$ \\
\hline $\begin{array}{l}\text { Efeitos Aleatórios vs } \\
\text { Efeitos Fixos }\end{array}$ & $\begin{array}{l}\text { Hausman; H0 - efeitos individuais } \\
\text { são independentes dos regressores }\end{array}$ & $\begin{array}{c}\text { Rejeita-se H0 => } \\
\text { efeitos fixos }\end{array}$ \\
\hline
\end{tabular}

\subsection{Modelo 1 e hipóteses}

A especificação matemática inicial da relação económica entre o nível de donativos e as variáveis independentes, caracterizadas anteriormente, $\mathrm{Y}=\mathrm{f}(\mathrm{X}, \mathrm{u})$, é a seguinte (para o modelo pooled):

$\begin{aligned} \mathrm{Y}_{\mathrm{it}}= & \beta_{0}+\beta_{1} \mathrm{X}_{1 \mathrm{it}}+\beta_{2} \mathrm{X}_{2 \mathrm{it}}+\beta_{3} \mathrm{X}_{3 \mathrm{it}}+\beta_{4} \mathrm{X}_{4 \mathrm{it}}+\beta_{5} \mathrm{X}_{5 \mathrm{it}}+\beta_{6} \mathrm{X}_{6 \mathrm{it}}+ \\ & +\beta_{7} \mathrm{X}_{7 \mathrm{it}}+\mathrm{u}_{\mathrm{it}}\end{aligned}$

em que,

$\mathrm{Y}_{\mathrm{it}}=$ donativos ao abrigo do mecenato;

$\mathrm{X}_{1 \mathrm{it}}=$ custos com publicidade;

$\mathrm{X}_{2 \mathrm{it}}=$ dimensão (ativo);

$\mathrm{X}_{3 \mathrm{it}}=$ rendimento (resultados líquidos antes de impostos);

$\mathrm{X}_{4 \mathrm{it}}=$ rácio de leverage (passivo/capital próprio);

$\mathrm{X}_{5 \mathrm{it}}=$ setor de atividade: critério do grau de contacto com o público em geral (variável dummy que assume o valor "1", caso seja alto, e o valor "0" na hipótese alternativa);

$\mathrm{X}_{6 \mathrm{it}}=$ setor de atividade: critério ambiental (variável dummy que toma o valor " 1 ", se as empresas pertencerem ao grupo "poluentes", e o valor "0" nos restantes casos);

$\mathrm{X}_{7_{\mathrm{it}}}=$ taxa efetiva (IRC estimado/resultados líquidos antes de impostos); 
$\beta_{0}=$ parte constante do modelo;

$\beta_{\mathrm{k}}=$ coeficientes do modelo;

$\mathrm{u}_{\mathrm{it}}=$ parte residual do modelo.

Testar-se-ão as seguintes hipóteses:

$\mathrm{H}_{1}$ : Os custos com publicidade encontram-se positivamente relacionados com os donativos;

$\mathrm{H}_{2}$ : A dimensão de uma empresa tem uma relação positiva com os donativos;

$\mathrm{H}_{3}$ : A performance económico-financeira está positivamente relacionada com os donativos;

$\mathrm{H}_{4}$ : $\mathrm{O}$ nível de endividamento está negativamente relacionado com os donativos;

$\mathrm{H}_{5}$ : As empresas que tenham um contacto mais direto com o público revelam uma maior propensão para conceder donativos;

$\mathrm{H}_{6}$ : As empresas que tenham um maior impacto ambiental são mais propensas a conceder donativos;

$\mathrm{H}_{7}$ : A taxa efetiva de IRC está positivamente relacionada com os donativos.

De acordo com a literatura, espera-se que os coeficientes $\beta_{1}, \beta_{2}, \beta_{3}, \beta_{5}, \beta_{6}$ e $\beta_{7}$ sejam positivos e que o coeficiente $\beta_{4}$ seja negativo.

\subsection{Dados da amostra}

A literatura sugere que as características específicas de uma empresa condicionam o seu comportamento filantrópico. Neste sentido, Navarro (1988a), Boatsman e Gupta (1996) e BuchHoltz et al. (1999) sustentam que as estatísticas agregadas não fornecem uma perspetiva rigorosa do quadro da filantropia organizacional. 
Entre nós, não é tarefa fácil aceder a estatísticas individuais. A investigação empírica que inclua variáveis fiscais depara-se, habitualmente, com alguns problemas na obtenção de dados.

Não obstante, conseguimos obter dados individuais através da Direcção-Geral de Informática e Apoio aos Serviços Tributários (DGITA). Esta entidade disponibilizou-nos, para uma amostra de 368 sociedades e para os exercícios de 2002, 2003, 2004 e 2005, cujas informações gerais se encontram condensadas no quadro 2. Neste quadro também se aflora o modo de construção de algumas variáveis, que explicaremos mais adiante.

Os critérios fixados para a seleção da amostra foram: sociedades anónimas residentes em Portugal e, durante todo o período temporal referido, terem estado em funcionamento, apresentado declarações fiscais, concedido donativos e preenchido o Quadro 07 do Modelo 22 (declaração periódica de rendimentos).

A amostra circunscreve-se às sociedades anónimas em virtude da obrigação legal de revisão de contas que sobre estas impende, o que melhora a credibilidade da informação contabilístico-financeira, patente nos Modelos 22 do IRC e nas declarações anuais de informação contabilística e fiscal, doravante "declarações anuais". Paralelamente, esta opção traduz-se no afastamento automático do regime simplificado, que altera as taxas legais de imposto face ao regime geral do IRC.

Para garantir alguma comparabilidade, importa que os dados se refiram a um período de relativa estabilidade no que ao regime normativo-fiscal dos donativos diz respeito. Selecionou-se, pois, um período temporal em que o Estatuto do Mecenato vigorasse (entrou em vigor em 1999) e que, simultaneamente, abrangesse a vigência da Lei do Mecenato Científico, que produziu efeitos a partir do exercício de 2005. 
QUADRO 2 - Construção das variáveis

\begin{tabular}{|c|c|c|c|}
\hline Variáveis disponíveis & Campo & Impresso & $\begin{array}{c}\text { Variáveis } \\
\text { construídas }\end{array}$ \\
\hline Total de proveitos & A112 & declaração anual, anexo A & \multirow{6}{*}{$\begin{array}{c}\text { Resultados } \\
\text { líquidos } \\
\text { antes de } \\
\text { impostos }\end{array}$} \\
\hline Proveitos e ganhos financeiros & A110 & declaração anual, anexo A & \\
\hline $\begin{array}{l}\text { Proveitos e ganhos extraordi- } \\
\text { nários }\end{array}$ & A111 & declaração anual, anexo A & \\
\hline Total de custos & A122 & declaração anual, anexo A & \\
\hline Custos e perdas financeiros & A120 & declaração anual, anexo A & \\
\hline Custos e perdas extraordinários & A121 & declaração anual, anexo A & \\
\hline Resultado líquido do exercício & A124, A 123 & declaração anual, anexo A & \multirow{2}{*}{$\begin{array}{l}\text { Resultados } \\
\text { líquidos } \\
\text { antes de } \\
\text { impostos e } \\
\text { IRC esti- } \\
\text { mado }\end{array}$} \\
\hline Imposto sobre o rendimento & 211 & Modelo 22, Quadro 07 & \\
\hline Passivo & A 240 & declaração anual, anexo A & \multirow{2}{*}{$\begin{array}{c}\text { Ativo, } \\
\text { Passivo e } \\
\text { Capital } \\
\text { Próprio }\end{array}$} \\
\hline Capital Próprio & A 235 & declaração anual, anexo A & \\
\hline Custos com publicidade & A 343 & declaração anual, anexo A & $\begin{array}{l}\text { Custos com } \\
\text { publicidade }\end{array}$ \\
\hline $\begin{array}{l}\text { CAE (classificação portuguesa } \\
\text { das atividades económicas) }\end{array}$ & 4 & $\begin{array}{l}\text { declaração anual, folha de } \\
\text { rosto }\end{array}$ & CAE \\
\hline $\begin{array}{l}\text { Donativos não previstos ou para } \\
\text { além dos limites legais }\end{array}$ & 210 & Modelo 22, Quadro 07 & \multirow{11}{*}{ Donativos } \\
\hline Beneficios Fiscais & 234 & Modelo 22, Quadro 07 & \\
\hline $\begin{array}{l}\text { Majorações aplicadas nos ter- } \\
\text { mos do Estatuto do Mecenato }\end{array}$ & F123 & declaração anual, anexo F & \\
\hline Mecenato social e familiar & F374 & declaração anual, anexo F & \\
\hline Mecenato cultural & F375 & declaração anual, anexo F & \\
\hline Mecenato ambiental & F376 & declaração anual, anexo $\mathrm{F}$ & \\
\hline $\begin{array}{l}\text { Mecenato científico e tecno- } \\
\text { lógico }\end{array}$ & F377 & declaração anual, anexo F & \\
\hline Mecenato desportivo & F378 & declaração anual, anexo F & \\
\hline Mecenato educacional & F379 & declaração anual, anexo $\mathrm{F}$ & \\
\hline $\begin{array}{l}\text { Mecenato sociedade de infor- } \\
\text { mação }\end{array}$ & F380 & declaração anual, anexo F & \\
\hline Regimes especiais & F381 & declaração anual, anexo F & \\
\hline
\end{tabular}




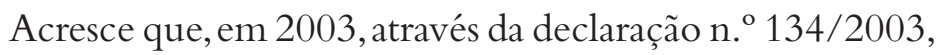
de 11 de Fevereiro de 2003, foram publicados, no Diário da República, II série, n. ${ }^{\circ}$ 74, de 28 de Março de 2003, os novos modelos de impressos, que se aplicam aos deveres declarativos relativos ao exercício de 2002. Esta alteração dos impressos, que compõem a declaração anual, tem impacto na recolha de dados, na medida em que a informação solicitada à DGITA foi feita com base nos diversos campos desses impressos. Por razões de simplicidade e fiabilidade da informação, é conveniente que, ao longo do período observado, os dados solicitados constassem de impressos similares.

Por todos os motivos expostos, e porque na data do pedido endereçado à DGITA os dados de 2006 ainda não estavam disponíveis, o período temporal analisado é composto pelos exercícios de 2002, 2003, 2004 e 2005. Refira-se, por fim, que, do cruzamento de informação feito com base nos Modelos 22 e nas declarações anuais, verificámos inconsistências em 59 empresas. Foram estas retiradas da amostra, conduzindo a um número total de empresas de 309 entidades. Assim, a amostra final é composta por quatro períodos $(\mathrm{T}=4)$ e 309 empresas $(\mathrm{N}=309)$.

De seguida, descrevem-se algumas variáveis, explicando o modo como foram obtidas.

\subsection{Variável dependente: total de donativos}

A declaração anual, a que aludem os art. $117 .^{\circ}$, n. ${ }^{\circ} 1$, alínea c), e $121 .^{\circ}$ do CIRC, estabelece no seu Anexo F, campo F123 do quadro 04, a inclusão do total de majorações aceites fiscalmente. Estas majorações são deduzidas no Quadro 07 do Modelo 22, linha $234^{13}$. A declaração anual também prevê a

13 Neste sentido, a informação vinculativa relativa ao processo n. ${ }^{\circ} 442 / 08$, com despacho do Substituto Legal do Diretor-Geral dos 
inscrição dos donativos atribuídos ao abrigo do regime do mecenato, quando superiores a 5 euros, majorados, nos campos F374 e seguintes do quadro 07 do seu Anexo $\mathrm{F}^{14}$.

No quadro 07 do Anexo F da declaração anual, os vários tipos de donativos são repartidos em função da sua natureza: social, familiar, cultural, ambiental, científico e tecnológico, desportivo, educacional e sociedade de informação. Os valores dos donativos que se enquadram nesta tipologia legal e que excedem os limites fiscais fixados no mecenato têm o mesmo tratamento dos donativos não previstos neste regime: são acrescidos ao lucro tributável (Quadro 07 do Modelo 22, linha 210).

Em face do exposto, o valor dos donativos concedidos ao abrigo do mecenato obtém-se através da subtração entre o total dos campos F374 e seguintes do quadro 07 e o valor das majorações contempladas no campo F123 do quadro 04 da declaração anual.

\subsection{Variáveis dummy: setor de atividade}

Já foi anteriormente referido que o sector de atividade surge, frequentemente, na literatura como uma variável explicativa dos donativos. Em alguns estudos espera-se, a priori, que as empresas que têm maior contacto com o público concedam mais donativos. Sob outro prisma, sustenta-se que

\footnotetext{
Impostos, em 7/4/2008, estipula que "considerando que o montante do donativo já está refletido no resultado líquido do exercício, Campo 201 do Q.07 da declaração periódica de rendimentos (Mod. 22), há apenas que deduzir no Campo 234 desse Q.07 o valor da respetiva majoração para efeitos da consideração do benefício fiscal na sua totalidade".

${ }^{14}$ Este campo acolhe o total de donativos mecenáticos, independentemente de excederem os limites fiscais, adicionado da respetiva majoração que é aceite como dedução ao rendimento.
} 
as empresas que operam em setores de atividade que causam maiores externalidades negativas, nomeadamente ambientais, têm uma atividade filantrópica mais intensa.

Relativamente à primeira perspetiva, foram feitos esforços de procurar na literatura uma distribuição da CAE segundo o critério do grau de contacto com o público. No entanto, não encontrámos referências apropriadas. Assim, procedeu-se à seleção dessas atividades, seguindo um critério de razoabilidade, que se descreverá de seguida. De acordo com a CAE Rev. 2.1 (Decreto-Lei n. ${ }^{\circ}$ 197/2003, de 27 de Agosto), considerou-se que as divisões agregadoras das entidades que operam, principalmente, sob um modelo business-to-consumer $(B 2 C)$, ou seja, que têm um elevado contacto direto com o público em geral, são as seguintes:

52 - Comércio a retalho (exceto de veículos automóveis, motociclos e combustíveis para veículos); reparação de bens pessoais e domésticos;

55 - Alojamento e restauração (restaurantes e similares);

64 - Correios e telecomunicações;

65 - Intermediação financeira, exceto seguros e fundos de pensões;

66 - Seguros, fundos de pensões e outras atividades complementares de segurança social;

67 - Atividades auxiliares de intermediação financeira;

80 - Educação;

85 - Saúde e ação social;

92- Atividades recreativas, culturais e desportivas;

93 - Outras atividades de serviços.

Para além destas divisões, na sequência de uma análise mais desagregada, acrescentaram-se ao grupo das empresas $B 2 C$ as seguintes atividades:

40130 - Distribuição e comércio de eletricidade; 
45211 - Construção de edifícios;

45212 - Construção e engenharia civil;

50100 - Comércio de veículos automóveis;

50300 - Comércio de peças e acessórios para veículos automóveis;

60211 - Transportes urbano e local por metropolitano, elétrico, troleicarro e autocarro;

63300 - Agências de viagens e de turismo e de outras atividades de apoio turístico;

70110 - Promoção imobiliária;

70120 - Compra e venda de bens imobiliários;

70200 - Arrendamento de bens imobiliários;

71100 - Aluguer de veículos automóveis.

Na sequência desta classificação, na amostra utilizada o grupo B2C compõe-se de 86 empresas e o grupo B2B (business-to-business) de 223. Esta classificação origina a variável $\mathrm{X}_{5 \mathrm{it}}$ (sector de atividade: critério do grau de contacto com o público em geral), que assume a forma de variável dummy (toma o valor "1", caso a empresa pertença ao grupo B2C, e o valor "0" na hipótese de pertencer ao grupo B2B).

No que se refere à segunda perspetiva, que se baseia no impacto ambiental das empresas, a classificação foi feita segundo as estatísticas do INE resumidas no quadro 3. Tendo em consideração os dados referentes às emissões de dióxido carbono, as empresas pertencentes às divisões 23, 24, 26, 40-41, 45 e 60-64 são as que apresentam valores mais elevados. Estes sectores foram responsáveis por $64,9 \%, 63,0 \%, 62,8 \%$ e $65,1 \%$ do total de emissões de dióxido de carbono em 2005, 2004, 2003 e 2002, respetivamente. 


\section{QuADro 3 - Emissões de dióxido de carbono, 2002, 2003, 2004 e 2005}

\begin{tabular}{|c|c|c|c|c|c|}
\hline \multirow[t]{2}{*}{ Ramo de atividade } & \multirow[t]{2}{*}{$\begin{array}{l}\text { CAE / } \\
\text { Divisão }\end{array}$} & \multicolumn{4}{|c|}{$\begin{array}{c}\text { Emissões de dióxido } \\
\text { de carbono } \\
\text { (milhares de toneladas) }\end{array}$} \\
\hline & & 2005 & 2004 & 2003 & 2002 \\
\hline $\begin{array}{l}\text { Agricultura, produção animal, caça e } \\
\text { silvicultura }\end{array}$ & 01,02 & 710 & 775 & 834 & 1015 \\
\hline Pesca & 05 & 224 & 310 & 273 & 341 \\
\hline Extração de produtos energéticos & $10,11,12$ & - & - & - & - \\
\hline $\begin{array}{l}\text { Indústrias extrativas com a exceção } \\
\text { da extração de produtos energéticos }\end{array}$ & 13,14 & 740 & 714 & 690 & 713 \\
\hline $\begin{array}{l}\text { Indústrias alimentares, das bebidas e } \\
\text { do tabaco }\end{array}$ & 15,16 & 1047 & 1209 & 1412 & 1479 \\
\hline Indústria têxtil & 17,18 & 1238 & 1252 & 1334 & 1392 \\
\hline $\begin{array}{l}\text { Indústria do couro e de produtos do } \\
\text { couro }\end{array}$ & 19 & 28 & 27 & 29 & 30 \\
\hline $\begin{array}{l}\text { Indústrias da madeira e da cortiça e } \\
\text { suas obras }\end{array}$ & 20 & 316 & 330 & 312 & 309 \\
\hline $\begin{array}{l}\text { Indústria de pasta, de papel e cartão e } \\
\text { seus artigos; edição e impressão }\end{array}$ & 21,22 & 1502 & 1430 & 1273 & 1273 \\
\hline $\begin{array}{l}\text { Fabricação de coque, produtos pe- } \\
\text { trolíferos refinados e combustível } \\
\text { nuclear }\end{array}$ & 23 & 3307 & 3353 & 3227 & 3287 \\
\hline $\begin{array}{l}\text { Fabricação de produtos químicos e } \\
\text { de fibras sintéticas ou artificiais }\end{array}$ & 24 & 4121 & 4066 & 3741 & 3598 \\
\hline $\begin{array}{l}\text { Fabricação de artigos de borracha e } \\
\text { de matérias plásticas }\end{array}$ & 25 & 149 & 151 & 144 & 138 \\
\hline $\begin{array}{l}\text { Fabricação de outros produtos mine- } \\
\text { rais não metálicos }\end{array}$ & 26 & 8353 & 8384 & 8354 & 8842 \\
\hline $\begin{array}{l}\text { Indústrias metalúrgicas de base e de } \\
\text { produtos metálicos }\end{array}$ & 27,28 & 374 & 343 & 376 & 360 \\
\hline $\begin{array}{l}\text { Fabricação de máquinas e de equi- } \\
\text { pamentos, n.e. }\end{array}$ & 29 & 288 & 289 & 299 & 286 \\
\hline $\begin{array}{l}\text { Fabricação de equipamento elétrico } \\
\text { e de ótica }\end{array}$ & $30,31,32,33$ & 39 & 37 & 38 & 37 \\
\hline Fabricação de material de transporte & 34,35 & 31 & 26 & 25 & 24 \\
\hline Indústrias transformadoras, n.e. & 36,37 & 95 & 90 & 78 & 74 \\
\hline $\begin{array}{l}\text { Produção e distribuição de eletrici- } \\
\text { dade, gás e água }\end{array}$ & 40,41 & 20263 & $\begin{array}{c}17 \\
969\end{array}$ & $\begin{array}{c}16 \\
869\end{array}$ & $\begin{array}{c}21 \\
042\end{array}$ \\
\hline Construção & 45 & 3202 & 3242 & 3186 & 3310 \\
\hline $\begin{array}{l}\text { Comércio por grosso e a retalho; } \\
\text { reparação de veículos automóveis e } \\
\text { de bens de uso pessoal e doméstico }\end{array}$ & $50,51,52$ & 2391 & 2195 & 1706 & 1663 \\
\hline
\end{tabular}




\begin{tabular}{|c|c|c|c|c|c|}
\hline $\begin{array}{l}\text { Alojamento e restauração (restauran- } \\
\text { tes e similares) }\end{array}$ & 55 & 178 & 165 & 313 & 148 \\
\hline $\begin{array}{l}\text { Transportes, armazenagem e comu- } \\
\text { nicações }\end{array}$ & $60,61,62,63,64$ & 4674 & 4435 & 4816 & 4546 \\
\hline Atividades financeiras & $65,66,67$ & 9 & 10 & 16 & 14 \\
\hline $\begin{array}{l}\text { Atividades imobiliárias, alugueres e } \\
\text { serviços prestados às empresas }\end{array}$ & $70,71,72,73,74$ & 755 & 705 & 582 & 571 \\
\hline $\begin{array}{l}\text { Administração pública, defesa e } \\
\text { segurança social (obrigatória) }\end{array}$ & 75 & 1088 & 1169 & 1127 & 1079 \\
\hline Educação & 80 & 190 & 205 & 177 & 186 \\
\hline Saúde e ação social & 85 & 2511 & 2912 & 2841 & 2861 \\
\hline $\begin{array}{l}\text { Outras atividades de serviços coleti- } \\
\text { vos, sociais e pessoais }\end{array}$ & $90,91,92,93$ & 917 & 920 & 779 & 802 \\
\hline $\begin{array}{l}\text { Atividades das famílias com empre- } \\
\text { gados domésticos e atividades de } \\
\text { produção das famílias para uso pró- } \\
\text { prio }\end{array}$ & $95,96,97$ & - & - & - & - \\
\hline $\begin{array}{l}\text { Organismos internacionais e outras } \\
\text { instituições extraterritoriais }\end{array}$ & 99 & - & - & - & - \\
\hline Famílias & - & 8867 & 9102 & 9192 & 9169 \\
\hline Transporte & - & 6552 & 6772 & 6865 & 6856 \\
\hline Aquecimento & - & 4 & 6 & 6 & 11 \\
\hline Outros & - & 2312 & 2324 & 2320 & 2302 \\
\hline Total de emissões & & 67608 & $\begin{array}{c}65 \\
816\end{array}$ & $\begin{array}{c}64 \\
043\end{array}$ & $\begin{array}{c}68 \\
589\end{array}$ \\
\hline
\end{tabular}

Fonte: INE, Emissões de dióxido de carbono (CO2) (Base 2000 - Kt), por ramo de atividade - Anual; INE, Conta Satélite do Ambiente.

Assim, o grupo das "mais poluentes" é constituído por 84 empresas e o outro por 225. Desta classificação resulta a construção da variável dummy $\mathrm{X}_{\text {6it }}$ (sector de atividade: critério ambiental) que assume o valor " 1 ", se a CAE das empresas pertencer a uma das divisões "poluentes", e o valor "0" nos restantes casos. 


\subsection{Resultados líquidos antes de impostos e IRC esti- mado}

Os resultados líquidos antes de impostos foram calculados subtraindo o total de custos ao total de proveitos. Corresponde no Anexo $\mathrm{A}$ da declaração anual à diferença entre os campos A112 e A122. Este valor também pode ser obtido através da soma do campo A124 com o A123.

Uma questão que importa aqui aclarar prende-se com o valor do IRC do exercício. O valor do IRC estimado está inscrito no campo A123 da declaração anual. Porém, este valor difere do valor do IRC inscrito no Modelo 22, Quadro 07, linha 211 (é o caso de 58 empresas, ainda que apenas em alguns exercícios).Vejamos porquê.

Em obediência ao art. $104 .^{\circ}$, n. $^{\circ} 2$ da CRP, que remete para o índice da capacidade contributiva das empresas, o IRC incide, por via de regra, sobre o lucro real ${ }^{15}$. O rendimento tributável das empresas é obtido, em primeira instância, através de cálculos e regras contabilísticos e decorre da aplicação da teoria do acréscimo patrimonial, ou teoria do balanço. Corresponde à variação do ativo líquido durante o período de tributação (art. $3 .^{\circ}$, n. $^{\circ} 2$ do CIRC).

${ }^{15}$ De acordo com as normas de incidência subjetiva do CIRC - art. 2. ${ }^{\circ}$, n. $^{\circ} 1$, alíneas a) e b) - e objetiva - art. $3 .^{\circ}$, n. $^{\circ} 1$, alínea a) -, o IRC incide sobre os lucros das pessoas coletivas com sede ou direção efetiva em Portugal, que exercem principalmente atividades comerciais, industriais ou agrícolas. O CIRC assume que as sociedades comerciais ou civis sob forma comercial, as cooperativas e as empresas públicas exercem, a título principal, o comércio, a indústria ou a agricultura, ou seja, "realizam operações económicas de carácter empresarial, incluindo as prestações de serviços" (art. 3. ${ }^{\circ},{ }^{\circ}{ }^{\circ} 4$ do CIRC). Para a legislação fiscal, estas atividades são intrínsecas à natureza daquelas entidades. Apesar de o IRC variar de acordo com a categoria jurídica e a residência dos sujeitos passivos, uma vez que a nossa amostra é constituída por sociedades comerciais com sede ou direção efetiva em Portugal, centrar-nos-emos na tributação deste tipo de pessoas coletivas, que tem por base, como se disse já, o lucro. 
No Modelo 22, as discrepâncias entre os resultados contabilístico e fiscal estão patentes no seu Quadro 07, que visa o apuramento do lucro tributável ou do prejuízo fiscal. A sua construção tem início no resultado líquido do exercício dado pela contabilidade, cujo valor é inscrito na linha 201 e que coincide com o do campo A124 do Anexo A da declaração anual.

Entre vários montantes a deduzir e a acrescer, encontram-se duas correções no Quadro 07 do Modelo 22 relacionadas com o efeito dos impostos diferidos. A primeira, constante na linha 211 , segundo o art. $45 .^{\circ},{ }^{\circ}{ }^{\circ} 1$, alínea a) do CIRC, é o IRC (que, naturalmente, integra as tributações autónomas ${ }^{16}$ ) e outros impostos incidentes direta ou indiretamente sobre lucros (de que é exemplo a derrama ${ }^{17}$. O valor a indicar nesta linha corresponde ao do campo A123 do Anexo A da declaração anual, ressalvado o caso de ter havido reconhecimento contabilístico dos efeitos dos impostos diferidos. Nesta hipótese, o efeito dos impostos diferidos deverá ser refletido no

${ }^{16}$ As taxas de tributação autónoma, cada vez mais frequentes no CIRC, são uma das razões que explicam que haja IRC a pagar e, simultaneamente, resultados líquidos negativos. Estão previstas no art. $88 .^{\circ}$ deste Código.

${ }^{17}$ Note-se que o campo 358 do quadro 10 do Modelo 22, intitulado "IRC Liquidado", não contempla nem as tributações autónomas, nem a derrama (imposto municipal que incide na coleta de IRC), que são duas componentes relevantes da carga fiscal do exercício. De acordo com as estatísticas oficiais (IRC - Declarações do IRC, de 2002-2004 e 2003-2005, da Direcção-Geral dos Impostos), o valor do IRC liquidado efetivo, que corresponde à soma do IRC liquidado com os pagamentos especiais por conta (estão inscritos no campo 356 do quadro 10 do Modelo 22 como deduções à Coleta, mas configuram um pagamento antecipado do imposto), totalizou 3088 milhões de euros em 2002, 3318 em 2003, 3037 em 2004 e 2932 em 2005. O valor das tributações autónomas e da derrama ascendeu a 471, 497, 459 e 460 milhões de euros em 2002,2003, 2004 e 2005, respetivamente. 
Quadro 07 do Modelo $22^{18}$. Ou seja, caso os efeitos dos impostos diferidos tenham sido objeto de relevação contabilística ao abrigo da DC n. ${ }^{\circ} 28$ (Impostos sobre o rendimento) ${ }^{19}$, o campo A123 da declaração anual não coincide com a linha 211 do Quadro 07 do Modelo 22. Neste impresso, o valor daquele campo é separado em duas componentes: o IRC estimado e os efeitos dos impostos diferidos. Assim, o valor constante na linha 211 do Quadro 07 funciona como uma aproximação mais fiel ao IRC do exercício.

Para uma melhor compreensão desta opção, sintetizam-se os principais aspetos dos impostos diferidos. A regulamentação relativa aos impostos diferidos surge na esteira da excessiva interferência das normas fiscais na prestação de contas e constitui um sinal inequívoco da autonomia das regras contabilísticas, a que o Sistema de Normalização Contabilística (SNC) veio dar força. Existem diferenças entre os valores dos ativos e dos passivos escriturados de acordo com os critérios de mensuração da contabilidade e as respetivas bases fiscais. Podem ser temporárias (resultam de valores suscetíveis de compensação em períodos subsequentes ou que são a compensação de diferenças de períodos anteriores), ou definitivas, quando as diferenças entre o lucro tributável e o resultado contabilístico de um exercício não revertem nos períodos seguintes, sendo constituídas, por exemplo, por gastos e rendimentos sem relevância fiscal. Estas diferenças, em particular as temporárias, implicam a necessidade de adoção dos métodos dos efeitos tributários.

${ }^{18}$ A partir de Janeiro de 2006, este impresso passou a conter, expressamente, as linhas 271 e 273 (a acrescer e a deduzir respetivamente).

${ }^{19}$ No período a que os dados se referem, vigoravam o $\mathrm{POC}$ e as DC. Mas esta matéria não sofreu grandes alterações no âmbito do SNC. A DC n. ${ }^{\circ} 28$ tem como referência a norma internacional de contabilidade n. ${ }^{\circ} 12$, daí que o seu conteúdo essencial tenha sido transposto para a NCRF n. ${ }^{\circ} 25$, que trata sobre esta temática no SNC. 
Por um lado, a estimativa do IRC, determinada de acordo com as regras fiscais, é o último lançamento contabilístico do exercício (a este lançamento subjaz o método do imposto a pagar). Por outro, a DC n. ${ }^{\circ} 28$, que entrou em vigor em Janeiro de 2003, evidencia que este método, seguido pelo POC, é pouco coerente com o "objetivo da imagem verdadeira e apropriada da posição financeira e dos resultados".

De facto, a insuficiência técnica deste método no que ao tratamento das diferenças temporárias diz respeito (não prevê a sua periodização), traduz-se no desrespeito pelos princípios da prudência e do acréscimo, afetando a comparabilidade das demonstrações financeiras (DF). De acordo com esta norma, salvo algumas exceções, as diferenças tributárias temporárias, no caso de serem dedutíveis, originam o reconhecimento de ativos por impostos diferidos. $\mathrm{Na}$ hipótese inversa, ou seja, caso aquelas diferenças sejam tributáveis, relevam-se passivos por impostos diferidos na contabilidade. Por exemplo, a contabilização de perdas por imparidade em créditos, pela respetiva totalidade, sem atender ao critério temporal previsto na legislação fiscal (art. 36. ${ }^{\circ},{ }^{\circ}{ }^{\circ} 2$ do CIRC), tem por consequência que a base contabilística do ativo seja inferior à sua base fiscal. Ou seja, um gasto contabilístico anterior ao gasto fiscal. Daqui decorre uma diferença temporária dedutível, reconhecendo-se um ativo por impostos diferidos - estas diferenças vão ser dedutíveis ao resultado fiscal de períodos futuros.

Logo, o cálculo do IRC, segundo o método dos impostos diferidos, distancia-se do valor de IRC que será efetivamente apurado de acordo com as normas fiscais, impondo, tal como mencionámos, correções no Quadro 07 do Modelo 22. No método do imposto a pagar, o valor do imposto é calculado tendo por base a matéria coletável do período.

O IRC estimado surge como o valor apropriado para a construção das variáveis que têm em linha de conta o imposto do exercício corrente, porque é calculado de acordo com as 
regras fiscais. A expressão "IRC estimado" deriva do procedimento adotado aquando do encerramento de contas, que visa responder ao desfasamento temporal entre esta data e o preenchimento do Modelo 22.

De tudo quanto antecede, o valor do IRC estimado utilizado no tratamento de dados revela-se credível, porque é cruzado com outros valores dos campos da declaração anual e está patente nas DF reportadas ao final do exercício, tendo sido auditado (note-se que o art. $121 .^{\circ}$, n. $^{\circ}$ 5, do CIRC obriga à concordância entre os elementos da declaração anual e os da contabilidade ou registos de escrituração). No entanto, o seu rigor encontra limites nas correções técnicas à avaliação da matéria coletável, decorrentes de um eventual procedimento de inspeção da Administração fiscal, e na substituição das declarações por iniciativa do sujeito passivo. Estas limitações são comuns e assumidas pelas estatísticas oficiais do IRC.

\subsection{Apresentação dos dados}

Tendo como referência os valores apresentados no quadro 4, o valor dos donativos em cada um dos quatro exercícios difere muito entre si e não se vislumbra qualquer tendência temporal. $\mathrm{O}$ rácio entre o total de donativos e o número de empresas da amostra (309) ascendeu a 46081 euros em 2002, 181147 em 2003, 115741 em 2004 e a 39205 euros em 2005.

Durante o período analisado, o ano de 2003 representa 47\% do total, em contraste com 2005 que representa apenas $10 \%$ do total dos donativos. O valor dos donativos majorados, em comparação com o simples valor dos donativos, é relativamente instável, sendo superior numa taxa que oscila entre os 4,4\% (2003) e os 29,9\% (2005). Uma interpretação mais ligeira poderia encarar este resultado como sendo surpreendente, 
uma vez que a percentagem das majorações fiscais legalmente previstas para os diversos tipos de mecenato é relativamente estável ao longo do período analisado. Porém, relembre-se que o valor dos donativos majorados acolhe não só as majorações aceites fiscalmente, como também os donativos ao abrigo do mecenato que não têm relevância fiscal, por força de ultrapassarem os limites fixados na lei, cuja referência é o volume de vendas.

À medida que aumenta o valor dos donativos concedidos, diminui o valor relativo das majorações. Há um excedente de donativos mecenáticos que é desqualificado para efeitos de dedução ao rendimento, sendo que, obviamente, as majorações apenas incidem na base dos donativos que é aceite para efeitos fiscais. Daí que, ao longo dos quatro exercícios, o valor relativo dos donativos não aceites, face ao valor dos donativos, não seja constante (varia entre os 9,2\% em 2002 e os $61,7 \%$ em 2005). Os resultados desta proporção, em particular para 2005, sugerem que as empresas canalizam donativos para causas e recipientes que não estão abrangidos pelo regime do mecenato, ou que o fazem ultrapassando os limites fiscais nele consagrados.

Por outro lado, somar o valor dos donativos não aceites com o valor dos donativos evidenciados no quadro, com o objetivo de calcular o valor total dos donativos (independentemente de serem concedidos ao abrigo do mecenato) resultaria num erro de duplicação: os valores dos donativos mecenáticos e que excedem as respetivas balizas estão incluídos nos donativos não aceites.

No que se refere à repartição dos donativos pelos vários tipos de mecenato, apresentada no quadro 5, conclui-se que o mecenato social e familiar é, invariavelmente, ao longo do período temporal, a causa preferida das empresas. Representa, em relação aos donativos majorados 52\%, 63\%, 89\% e 69\%, em 2002, 2003, 2004 e 2005, respetivamente. 
QuAdro 4 - Donativos, resultados e IRC das empresas

\begin{tabular}{|l|c|c|c|c|c|}
\hline \multicolumn{1}{|c|}{ ANO } & $\mathbf{2 0 0 2}$ & $\mathbf{2 0 0 3}$ & $\mathbf{2 0 0 4}$ & $\mathbf{2 0 0 5}$ & Total \\
\hline $\begin{array}{l}\text { Donativos não } \\
\text { aceites }\end{array}$ & 1.314 .513 & 13.800 .460 & 7.080 .328 & 7.476 .493 & 29.671 .793 \\
\hline Donativos & 14.239 .109 & 55.974 .492 & 35.763 .947 & 12.114 .493 & 118.092 .041 \\
\hline $\begin{array}{l}\text { Donativos } \\
\text { majorados }\end{array}$ & 16.036 .210 & 58.447 .475 & 38.672 .302 & 15.731 .986 & 128.887 .973 \\
\hline $\begin{array}{l}\text { Resultados } \\
\text { líquidos antes } \\
\text { de impostos }\end{array}$ & 1.646 .027 .587 & 1.786 .443 .681 & 2.326 .662 .855 & 2.056 .614 .626 & 7.815 .748 .749 \\
\hline IRC & 1.531 .584 .160 & 1.026 .754 .237 & 1.559 .813 .695 & 852.226 .637 & 4.970 .378 .730 \\
\hline
\end{tabular}

Fonte: DGITA.

\section{QuAdro 5 - Distribuição dos donativos}

\begin{tabular}{|c|c|c|c|c|c|c|c|c|c|c|}
\hline \multirow{3}{*}{$\begin{array}{c}\begin{array}{c}\text { Donativos } \\
\text { majorados }\end{array} \\
\text { segundo o tipo } \\
\text { de mecenato }\end{array}$} & \multicolumn{8}{|c|}{ ANO } & \multirow{2}{*}{\multicolumn{2}{|c|}{ Total }} \\
\hline & \multicolumn{2}{|l|}{2002} & \multicolumn{2}{|l|}{2003} & \multicolumn{2}{|l|}{2004} & \multicolumn{2}{|l|}{2005} & & \\
\hline & 8.292 .993 & $52 \%$ & 36.730 .546 & $63 \%$ & 34.235 .231 & $89 \%$ & 10.853 .975 & $69 \%$ & 90.112 .745 & $69,92 \%$ \\
\hline Cultural & 3.901 .720 & $24 \%$ & 3.810 .034 & $7 \%$ & 2.319 .713 & $6 \%$ & 1.901 .427 & $12 \%$ & 11.932 .894 & $9,26 \%$ \\
\hline Ambiental & 18.358 & $0 \%$ & 334.688 & $1 \%$ & 56.155 & $0 \%$ & 893.297 & $6 \%$ & 1.302 .498 & $1,01 \%$ \\
\hline $\begin{array}{l}\text { Científico e } \\
\text { tecnológico }\end{array}$ & 246.529 & $2 \%$ & 169.474 & $0 \%$ & 533.274 & $1 \%$ & 313.141 & $2 \%$ & 1.262 .418 & $0,98 \%$ \\
\hline Desportivo & 2.167 .623 & $14 \%$ & 17.195 .035 & $29 \%$ & 1.261 .411 & $3 \%$ & 948.367 & $6 \%$ & 21.572 .436 & $16,74 \%$ \\
\hline Educacional & 281.469 & $2 \%$ & 202.231 & $0 \%$ & 255.803 & $1 \%$ & 485.109 & $3 \%$ & 1.224 .612 & $0,95 \%$ \\
\hline $\begin{array}{c}\text { Sociedade de } \\
\text { informação }\end{array}$ & 42.581 & $0 \%$ & 3.330 & $0 \%$ & 6.815 & $0 \%$ & 7.135 & $0 \%$ & 59.861 & $0,05 \%$ \\
\hline Regimes especiais & 1.084 .937 & $7 \%$ & 2.137 & $0 \%$ & 3.900 & $0 \%$ & 329.535 & $2 \%$ & 1.420 .509 & $1,10 \%$ \\
\hline Total & 16.036 .210 & $100 \%$ & 58.447 .475 & $100 \%$ & 38.672 .302 & $100 \%$ & 15.731 .986 & $100 \%$ & 128.887 .973 & $100 \%$ \\
\hline $\begin{array}{c}\text { Total de } \\
\text { Majorações }\end{array}$ & 1.797 .101 & $11 \%$ & 2.472 .983 & $4 \%$ & 2.908 .355 & $8 \%$ & 3.617 .493 & $23 \%$ & 10.795 .932 & $8 \%$ \\
\hline $\begin{array}{c}\text { Total de } \\
\text { Donativos }\end{array}$ & 14.239 .109 & $89 \%$ & 55.974 .492 & $96 \%$ & 35.763 .947 & $92 \%$ & 12.114 .493 & $77 \%$ & 118.092 .041 & $92 \%$ \\
\hline
\end{tabular}

Fonte: DGITA. 


\subsection{Resultados obtidos}

Considerando 309 empresas e quatro períodos temporais $(\mathrm{N}=309$ e $\mathrm{T}=4)$, o modelo estimado foi (modelo 1$)^{20}$ : $\log _{\text {Donativos }_{\text {it }}}=\beta_{0}+\beta_{1} \log$ Publicidade $_{\mathrm{it}}+\beta_{2} \log$ Activo $_{\mathrm{it}}+$ $\beta_{3} \log$ Resultados $_{\text {it }}+\beta_{4} \log$ Leverage $_{\text {it }}+\beta_{5}$ DummyPúblico $_{\text {it }}+$ $\beta_{6}$ DummyAmbiente $_{\text {it }}+\beta_{7} \log$ TxEfetiva $_{\mathrm{it}}+\mathrm{u}_{\mathrm{it}}$

Depois de comparados os vários modelos, o mais satisfatório é o modelo com efeitos fixos. Apresenta-se de seguida a sua versão reduzida (omitindo-se as variáveis sem significância estatística $\left.^{21}\right)$ :

$\log$ Donativos $_{\text {it }}=0,216933 \log$ Resultados $_{\text {it }}+0,125386 \log -$ TxEfectiva $_{\mathrm{it}}+\mathrm{u}_{\mathrm{it}}$

\section{QuAdro 6 - Modelo com efeitos fixos reduzido}

\begin{tabular}{|l|c|c|c|l|}
\hline \multicolumn{1}{|c|}{ Variável } & Coeficiente & Estatística-t & \multicolumn{2}{|c|}{$\boldsymbol{p}$-value } \\
\hline $\log$ Resultados & 0,216933 & 3,4638 & 0,00056 & $\star \star \star$ \\
\hline $\log$ TxEfetiva & 0,125386 & 3,1917 & 0,00147 & $\star \star \star$ \\
\hline
\end{tabular}

Nota: ${ }^{\star \star \star} ;{ }^{\star \star} \mathrm{e}^{\star}$ representam níveis de significância de $1 \%, 5 \%$ e $10 \%$, respetivamente.

${ }^{20}$ De forma a mitigar os efeitos que os valores muito divergentes da média (outliers) têm nos resultados empíricos, normalizando-os, e, simultaneamente, a interpretar os resultados sob a forma de elasticidade, optou-se por logaritmizar o modelo. Com efeito, os modelos propostos na literatura sobre este tema são geralmente log-lineares - SCHWARTz (1968), ClotFelter (1985), Navarro (1988a), Arulampalam e Stoneman (1995), Boatsman e Gupta (1996), Buchholtz et al. (1999), Seifert et al. (2004), Brammer e Millington (2005), Brammer e Pavelin (2006) e Brammer et al. (2009) -, ou são totalmente logaritmizados - AdAms e Hardwick (1998) e CARroll e Joulfaian (2005). Naturalmente que este procedimento acarreta a "perda" de algumas observações, uma vez que torna impossível, por definição, a consideração de observações cujo valor é negativo ou nulo.

${ }^{21} \mathrm{O}$ modelo com efeitos fixos não aceita estimações com variáveis dummy, prevenindo o problema da multicolinearidade. O software utilizado (GRETL) retira-as automaticamente do modelo. 
Assim, corroboram-se as proposições $\mathrm{H}_{3}$ e $\mathrm{H}_{7}$, que postulavam que os resultados líquidos antes de imposto e a taxa efetiva se encontram positivamente relacionados com os donativos.

A significância estatística da variável fiscal sugere que a concessão de donativos concedidos pelas empresas portuguesas segue o modelo da maximização da utilidade do órgão de gestão, em detrimento do modelo da maximização de lucros (repita-se que, neste segundo modelo, a taxa de imposto e o montante de donativos concedidos são independentes). Esta relação é positiva e inelástica ${ }^{22}$.

\subsection{Elasticidade-preço dos donativos e modelo 2}

A doutrina dominante defende a fixação legal de um limite máximo para a dedutibilidade dos donativos, se a relação entre os donativos e a taxa efetiva for significativa. É o que acontece com o regime fiscal dos donativos em Portugal.

Porém, subsiste uma questão à qual nos propusemos responder: qual o valor da elasticidade-preço dos donativos? Este resultado é útil para a política fiscal, porque permite prever o efeito da variação da taxa de imposto no montante de donativos. E, nesta matéria, o ponto de corte $(-1)$ assume uma importância central.

Apresenta-se, de seguida, uma interpretação matemática. Represente-se o nível de donativos por D, a taxa de imposto sobre o rendimento das empresas por t e o preço dos donativos por $\mathrm{P}, \operatorname{com} \mathrm{P}=1-\mathrm{t}^{23}$.

${ }^{22}$ A discussão dos resultados deste primeiro modelo está desenvolvida em Taborda e Martins (2011).

${ }^{23}$ As variáveis $\mathrm{D}$ e $\mathrm{t}$ correspondem, respetivamente, às variáveis Donativos e TxEfetiva já apresentadas. Apenas se procedeu à substituição 
A aceitação da dedutibilidade fiscal dos donativos é eficiente, sob o ponto de vista público, se:

$$
\begin{aligned}
& \frac{\partial(\mathrm{D}-\mathrm{tD})}{\partial \mathrm{t}}>0<=> \\
& <=>\frac{\partial \mathrm{D}}{\partial \mathrm{t}}-\mathrm{D} \cdot \frac{\partial \mathrm{t}}{\partial \mathrm{t}}-\mathrm{t} \cdot \frac{\partial \mathrm{D}}{\partial \mathrm{t}}>0<=> \\
& <=>\frac{\partial \mathrm{D}}{\partial \mathrm{t}}-\mathrm{t} \cdot \frac{\partial \mathrm{D}}{\partial \mathrm{t}}-\mathrm{D}>0<=> \\
& <=>\frac{\partial \mathrm{D}}{\partial \mathrm{t}} \cdot(1-\mathrm{t})-\mathrm{D}>0<=> \\
& <=>\frac{\partial \mathrm{D}}{\partial \mathrm{t}} \cdot(1-\mathrm{t})>\mathrm{D}<=> \\
& <=>-\frac{\partial \mathrm{D}}{\partial(1-\mathrm{t})} \cdot(1-\mathrm{t})>\mathrm{D}^{24}<=> \\
& <=>\frac{\partial \mathrm{D}}{\partial(1-\mathrm{t})} \cdot \frac{1-\mathrm{t}}{\mathrm{D}}<-1<=> \\
& <=>\frac{\partial \mathrm{D}}{\partial \mathrm{P}} \cdot \frac{\mathrm{P}}{\mathrm{D}}<-1<=> \\
& \Sigma_{\mathrm{D}, \mathrm{P}}<-1 \\
&
\end{aligned}
$$

da sua notação para simplificar a apresentação.

$$
\begin{gathered}
{ }^{24} \frac{\partial \mathrm{D}}{\partial \mathrm{t}}=-\frac{\partial \mathrm{D}}{\partial(1-\mathrm{t})}, \text { pois, se } \mathrm{f}=1-\mathrm{t} \text {, aplicando a regra da cadeia, vem: } \\
\frac{\partial \mathrm{D}}{\partial \mathrm{t}}=\frac{\partial \mathrm{D}}{\partial \mathrm{f}} \cdot(-1)=-\frac{\partial \mathrm{D}}{\partial \mathrm{f}}=-\frac{\partial \mathrm{D}}{\partial(1-\mathrm{t})}
\end{gathered}
$$


Neste cenário, o aumento do nível de donativos, induzido pela diminuição do respetivo preço, excede a inerente perda de receita fiscal. Dito de outro modo, o valor de uma unidade monetária do Estado, utilizada para subsidiar determinadas atividades pela via fiscal, gera mais do que uma unidade monetária no seu financiamento. Num quadro de restrições orçamentais, este resultado ganha ainda mais pertinência.

Tendo em conta as notações propostas para as variáveis, a expressão seguinte demonstra que a elasticidade-preço dos donativos pode ser obtida através da elasticidade dos donativos em relação à taxa efetiva:

$$
\Sigma_{\mathrm{D}, \mathrm{P}}=\Sigma_{\mathrm{D}, \mathrm{t}} \cdot \frac{\mathrm{t}-1}{\mathrm{t}}=\Sigma_{\mathrm{D}, \mathrm{t}} \cdot \frac{-\mathrm{P}}{\mathrm{t}}
$$

Do primeiro modelo, $\Sigma_{\mathrm{D}, \mathrm{t}} \approx 0.125$

$$
\text { Logo, } \Sigma_{D, P}=0.125 \cdot \frac{\mathrm{t}-1}{\mathrm{t}}
$$

Note-se que, por regra, $t \in] 0,1\left[\right.$, pelo que $\frac{t-1}{t}<0 \Rightarrow$ $\Rightarrow \Sigma_{\mathrm{D}, \mathrm{P}}<0$

Adicionalmente, $\Sigma_{D, P}=-1$, se $0.125(\mathrm{t}-1)=-\mathrm{t}<=>$ $\mathrm{t}-1=-8 \mathrm{t}<=>\mathrm{t}=1 / 9=0.11(1)$

Assim, conclui-se que:

$$
\begin{aligned}
& \mathrm{t} \leq 1 / 9 \Rightarrow \Sigma_{\mathrm{D}, \mathrm{P}} \leq-1 \\
& \mathrm{t}>1 / 9 \Rightarrow \Sigma_{\mathrm{D}, \mathrm{P}}>-1
\end{aligned}
$$


Considerando o valor da taxa legal de IRC, à partida, a taxa efetiva das empresas será superior a 0.11(1), conduzindo à segunda condição. Infere-se, pois, que a relação entre os donativos e o respetivo preço é negativa e inelástica (compreendida entre -1 e 0$)$.

Porém, é visível que o valor da elasticidade-preço depende da taxa efetiva de cada empresa, não sendo passível de generalização.

Uma forma possível de confirmar que $\Sigma_{\mathrm{DP}}>-1$ passa por estimar um novo modelo, que serve o propósito específico de estudar a elasticidade-preço dos donativos, restringindo-se, portanto, à inclusão da única variável capaz de a traduzir adequadamente. Ou seja, o que se pretende estimar é o coeficiente $\beta_{1}$ associado ao seguinte modelo, que apresentamos seguindo a especificação pooled (modelo 2):

$$
\log (\mathrm{D}-\mathrm{tD})_{\mathrm{it}}=\beta_{0}+\beta_{1} \log _{\mathrm{it}}+\mathrm{u}_{\mathrm{it}}
$$

Neste modelo, a variável dependente representa a contribuição efetiva da empresa, dado um determinado nível de donativos. De facto, na hipótese de dedutibilidade fiscal dos donativos, o verdadeiro custo da empresa com a atribuição de donativos, no montante total de $\mathrm{D}$, corresponde a $\mathrm{D}$-tD.

Matematicamente,

$$
\begin{aligned}
& \frac{\partial \log (\mathrm{D}-\mathrm{tD})}{\partial \log \mathrm{t}}=\beta_{1}<=> \\
& \Leftrightarrow=\frac{\partial(\mathrm{D}-\mathrm{tD})}{\partial \mathrm{t}} \cdot \frac{\mathrm{t}}{\mathrm{D}-\mathrm{tD}}=\beta_{1}<=> \\
& <=>\frac{\partial \mathrm{D}(1-\mathrm{t})}{\partial \mathrm{t}}=\frac{\mathrm{D}(1-\mathrm{t})}{\mathrm{t}} \cdot \beta_{1}
\end{aligned}
$$


Como vimos, $\frac{\partial \mathrm{D}(1-\mathrm{t})}{\partial \mathrm{t}}<0<=>\Sigma_{\mathrm{D}, \mathrm{P}}>-1$

Logo $\Sigma_{\mathrm{D}, \mathrm{P}}>-1$, se $\beta_{1}<0$, uma vez que $\frac{\mathrm{D}(1-\mathrm{t})}{\mathrm{t}}$ é positivo, assumindo que $t \in] 0,1[$.

Considerando estas relações, construiu-se a variável D-t.D e estimaram-se os modelos pooled, com efeitos fixos e com efeitos aleatórios, que incidem num painel de dados não balanceado, com 925 observações, e cujos resultados se apresentam nos quadros seguintes.

QuAdro 7 - Modelo pooled

\begin{tabular}{|l|c|c|c|l|}
\hline \multicolumn{1}{|c|}{ Variável } & Coeficiente & Estatística-t & \multicolumn{2}{c|}{$\boldsymbol{p}$-value } \\
\hline Const & 7,5172 & 68,6629 & $<0,00001$ & $\star \star \star$ \\
\hline Logt & $-0,241202$ & $-4,7878$ & $<0,00001$ & $\star \star \star$ \\
\hline
\end{tabular}

QUADro 8 - Modelo com efeitos fixos

\begin{tabular}{|c|c|c|c|c|}
\hline \multicolumn{1}{|c|}{ Variável } & Coeficiente & Estatística-t & \multicolumn{2}{|c|}{ p-value } \\
\hline Logt & $-0,250931$ & $-5,3255$ & $<0,00001$ & $\star \star \star$ \\
\hline
\end{tabular}

QUADRO 9 - Modelo com efeitos aleatórios

\begin{tabular}{|l|c|c|c|l|}
\hline \multicolumn{1}{|c|}{ Variável } & Coeficiente & Estatística-t & \multicolumn{2}{c|}{ p-value } \\
\hline Const & 7,49874 & 56,1706 & $<0,00001$ & $\star \star \star$ \\
\hline $\log t$ & $-0,241607$ & $-5,7085$ & $<0,00001$ & $\star \star \star$ \\
\hline
\end{tabular}

Nota: ${ }^{\star \star \star} ;{ }^{\star \star} \mathrm{e}{ }^{\star}$ representam níveis de significância de $1 \%, 5 \%$ e $10 \%$, respetivamente.

No modelo pooled, a variável independente é estatisticamente significativa (a um nível de significância inferior a 1\%) e o sinal do respetivo coeficiente é o esperado. Nos três modelos estimados, o sinal do coeficiente desta variável mantém-se e o respetivo valor praticamente não sofre alterações.

Com o propósito de selecionar o modelo mais apropriado, segundo o teste F, rejeita-se a hipótese de o modelo pooled ser 
adequado em favor do modelo com efeitos fixos [F $(290,633)$ $=6,53001$, com $p$-value $=4,16739 \mathrm{e}-086]$. Por outro lado, o teste de Breusch-Pagan ( $\mathrm{LM}=443,373)$ indica que o modelo com efeitos aleatórios é mais ajustado do que o modelo pooled ( $p$-value $=1,99668 \mathrm{e}-098)$. Por fim, segundo o teste de Hausman, as estimativas do modelo com efeitos aleatórios são consistentes $(\mathrm{H}=0,202728$, com $p$-value $=0,652528)$.

Infere-se, pois, que o modelo mais adequado é:

$\log (\mathrm{D}-\mathrm{tD})_{\mathrm{it}}=7,49874-0,241607 \log \mathrm{t}_{\mathrm{it}}+\mathrm{u}_{\mathrm{it}}$

Em conjunto, os resultados sugerem que a elasticidade-preço dos donativos está compreendida entre -1 e 0.

$O$ valor do coeficiente $\beta_{1}$ significa que, coeteris paribus, um aumento de $10 \%$ na taxa efetiva da empresa traduz-se numa redução de $2,4 \%$ no custo efetivo que esta incorre com a concessão de donativos. Ou seja, a contribuição relativa da empresa no custo total dos donativos diminui à medida que a taxa efetiva aumenta. Daqui decorre que a comparticipação relativa do Estado, por via da receita fiscal de que abdica, aumenta.

\section{Conclusões e Limitações do Estudo}

São necessárias várias ações no campo social para conferirem o estatuto de empresa socialmente responsável. Neste contexto, os donativos constituem um instrumento de demonstração explícita pública do empenho da empresa no domínio social e, quando alinhados com a estratégia, podem acarretar benefícios. Concorrem para a legitimação da empresa, reforçam a sua reputação e promovem a satisfação dos stakeholders.

A atuação do terceiro sector comporta diversas vantagens. Reforça os laços sociais, aprofunda o sentido de responsabili- 
dade cívica e de pertença, fortalece o pluralismo e aumenta o nível de participação e de exigência face ao bem-estar social. Num cenário de crise económica, as pessoas mais vulneráveis são as mais atingidas e, ao mesmo tempo, torna imperioso a criação de instrumentos de apoio a projetos inovadores capazes de inverter a tendência de recessão, propulsionando um sistema social mais justo, criativo e solidário.

O apoio do sector público ao terceiro sector pode ser feito de forma direta ou indireta. A subsidiação indireta é menos intrusiva. Deixa espaço para as pessoas demonstrarem as suas preferências, sinaliza de forma positiva a importância da generosidade privada e exige que as entidades do terceiro sector adotem técnicas de captação de fundos, reforçando a sua independência face ao sector público (sem prejuízo da sua monitorizaçã ${ }^{25}$ ), acarretando ganhos num contexto concorrencial saudável.

Não obstante, mesmo neste quadro de incentivo público têm de ser estabelecidos limites. O trade-off entre a redução da receita fiscal, motivada pela consideração da dedutibilidade do valor majorado dos donativos ao rendimento tributável em IRC, e as vantagens sociais inerentes à adoção de determinados comportamentos de reconhecido interesse público tem de ser equilibrado sob o ponto de vista orçamental.

Por outro lado, a relevância do preço dos donativos determina a imposição de "tetos máximos" na aceitação fiscal dos donativos, de forma a temperar o incentivo que promove a sua atribuição. Os nossos resultados reforçam a manutenção

${ }^{25}$ A transparência nesta matéria é essencial para prevenir que, à custa de donativos privados, algumas entidades beneficiárias, sob a roupagem do terceiro sector, ofereçam bens e serviços de mercado, com gravosas consequências na distorção da concorrência. Ademais, importa proceder a avaliações sistemáticas à sua atividade, garantindo que permanecem merecedoras da confiança que lhes foi endossada. As contrapartidas pelo estatuto especial que dispõem têm de ser permanentemente quantificadas. 
de um limite legal para a dedutibilidade dos donativos. Ou seja, o valor máximo fiscalmente dedutível dos donativos deve ser fixado legalmente, uma vez que a relação entre a taxa de imposto e os donativos mostrou ser significativa.

Também apontam, com grande margem de segurança, para uma relação negativa e inelástica (a elasticidade-preço em valor absoluto é inferior a um). Daqui decorre que o aumento dos donativos, induzido pelo respetivo preço, é proporcionalmente inferior à perda de receita fiscal associada ao benefício fiscal concedido. Dito de outro modo, os resultados obtidos prenunciam que a receita cessante, associada à aceitação da dedutibilidade fiscal dos donativos, é superior ao financiamento privado das entidades recipientes por via da atribuição de donativos. Daí que, sob o ponto de vista estritamente orçamental, seja preferível que o Estado proceda a transferências diretas para o terceiro setor.

Relativamente às limitações deste trabalho, que abrem pistas para investigação futura, salientamos que:

1) a performance económico-financeira seria melhor apurada por medidas de mercado em vez de terem uma raiz contabilística;

2) por razões de inércia, a CAE pode já não refletir a atividade predominante da empresa;

3) do cruzamento de informação efetuada, verificámos a declaração de informação inexata à administração fiscal, o que determinou a depuração da base de dados;

4) a amostra circunscreve-se às empresas que concedem donativos, desconsiderando a importância das características que diferenciam as outras;

5) muito embora seja reconhecida ao terceiro sector eficácia de atuação, não dispomos de qualquer resultado empírico que a ateste. O regime do mecenato corporiza um conjunto de benefícios fiscais que, por definição, acarretam despesa fiscal, pelo que os seus efeitos 
positivos deveriam ser quantificados. Seria desejável conjugar os resultados obtidos com uma análise sobre o contributo efetivo dos donativos privados para o bem-estar coletivo, já que têm sido alvo de comparticipação pública.

\section{BIBLIOGRAFIA}

Adams, M., Hardwick, P., 1998, “An Analysis of Corporate Donations: United Kingdom Evidence”, Journal of Management Studies, 35, pp. 641-654.

Амato, L.H., Амато, C.H., 2007, “The Effects of Firm Size and Industry on Corporate Giving”, Journal of Business Ethics, 72, pp. 229-241.

Arulampalam, W., Stoneman P., 1995, "An Investigation into the Givings by Large Corporate Donors to UK Charities: 1979-86”, Applied Economics, 27, pp. 935-945.

Backus, P., 2009, "Substituting Donkeys for Religion?: Testing the Homogeneity of Philanthropy", International Conference on The Economics of Charitable Giving, 8 e 9 de Outubro de 2009, Mannheim, Alemanha.

Baltagi, B.H., 1995, Econometric Analysis of Panel Data, John Wiley and Sons, New York.

Bennett, R., 1998, “Corporate Philanthropy in France, Germany and the UK: International Comparisons of Commercial Orientation towards Company Giving in European Nations", International Marketing Review, 15, pp. 458-475.

Boatsman, J.R., Gupta, S., 1996, “Taxes and Corporate Charity: Empirical Evidence from Micro-level Panel Data", National Tax Journal, 49, pp. 193-213.

Brammer, S., Millington, A., 2003, “The Evolution of Corporate Charitable Contributions in the UK between 1989 and 1999: Industry Structure and Stakeholder Influences", Business Ethics: A European Review, 12, pp. 216-228.

— - _ - 2004, "The Development of Corporate Charitable Contributions in the UK: A Stakeholder Analysis", Journal of Management Studies, 41, pp. 1411-1434.

— - — , 2005, "Corporate Reputation and Philanthropy: An Empirical Analysis", Journal of Business Ethics, 61, pp. 29-44. 
Brammer, S., Millington, A., 2006, "Firm Size Organizational Visibility and Corporate Philanthropy: An Empirical Analysis", Business Ethics: A European Review, 15, pp. 6-18.

—, Pavelin, S., 2005a, "Corporate Reputation and an Insurance Motivation for Corporate Social Investment", Journal of Corporate Citizenship, 20, pp. 39-51.

— _ _ 2 2005b, "Corporate Community Contributions in the United Kingdom and the United States", Journal of Business Ethics, 56, pp. 15$-26$.

—_ _ _ 2006, "Corporate Reputation and Social Performance: The Importance of Fit", Journal of Management Studies, 43, pp. 435-455.

— - — Porter, L., 2009, "Corporate Charitable Giving, Multinational Companies and Countries of Concern", Journal of Management Studies, 46, pp. 575-596.

Brown, W. O., Helland, E., Smith, J. K., 2006, “Corporate Philanthropy Practices”, Journal of Corporate Finance, 12, pp. 855-877.

Buchholtz, A.K., Amason, A.C., Rutherford, M.A., 1999, "Beyond Resources: The Mediating Effects of Top Management Discretion and Values on Corporate Philanthropy", Business and Society, 38, pp. 167-87.

Cain, J. E., Cain, A. S., 1985, “An Economic Analysis of Accounting Decision Variables Used to Determine the Nature of Corporate Giving”, Quarterly Journal of Business and Economics, Autumn, pp. 15-28.

Campbell, D., Moore, G., Metzger, M., 2002, "Corporate Philanthropy in the U.K. 1985-2000: Some Empirical Findings", Journal of Business Ethics, 39, pp. 29-41.

—, Stack, R., 2006, "Public Visibility as a Determinant of the Rate of Corporate Charitable Donations", Business Ethics: A European Review, 15, pp. 19-28.

Carroll, A.B., 1979, "A Three Dimensional Model of Corporate Performance”, Academy of Management Review, 4, pp. 497-505.

Carroll, R., Joulfaian, D., 2005, “Taxes and Corporate Giving to Charity", Public Finance Review, 33, pp. 300-317.

Casalta Nabais, J., 2008, "Política Fiscal, Desenvolvimento Sustentável e Luta contra a Pobreza", in Estudos de Direito Fiscal, Volume II, Almedina, Coimbra, 2008, pp. 41-65.

Choi, T.H., Jung, J., 2008, "Ethical Commitment, Financial Performance, and Valuation: An Empirical Investigation of Korean Companies", Journal of Business Ethics, 81, pp. 447-463.

Clotfelter, C.T., 1985, Federal Tax Policy and Charitable Giving, University of Chicago Press, Chicago. 
Cochran, P.L., Wood, R.A., 1984, “Corporate Social Responsibility and Financial Performance”, Academy of Management Journal, 27, pp. 42-56.

Day, K.M., Devlin, R.A., 2004, “Do Governments Expenditures Crowd Out Corporate Contributions?”, Public Finance Review, 32, pp. 404-425 .

Dunn, P., 2004, "Professional Corporate Donation Programs in Canada: An Exploratory Study", Nonprofit and Voluntary Sector Quarterly, 33, pp. 334-345.

Fernandes Ferreira, R., 2005, “As Instituições do Terceiro Sector”, Ciência e Técnica Fiscal, 415, pp. 246-258.

Figueiredo, M.C.T., Hill, M.M., 2003, "Dados em Painel: Painéis Genuínos vs Pseudo Painéis - Vantagens e Limitações”, in Reis, E., Hill, M.M., Temas em Métodos Quantitativos 3, Edições Sílabo, Lisboa, 2003, pp. 161-180.

Fry, L.M., Keim, G.D., Meiners, R.E., 1982, “Corporate Contributions: Altruistic or For-Profit?”, Academy of Management Journal, 25, pp. 94 $-106$.

Galaskiewicz, J., 1997, “An Urban Grants Economy Revisited: Corporate Charitable Contributions in the Twin Cities, 1979-81, 1987-89”, Administrative Science Quarterly, 42, pp. 445-471.

Gan, A., 2006, "The Impact of Public Scrutiny on Corporate Philanthropy", Journal of Business Ethics, 69, pp. 217-236.

Gardberg, N.A., Fombrun, C.J., 2006, "Corporate Citizenship: Creating Intangible Assets across Institutional Environments", Academy of Management Review, 3, pp. 329-346.

Godfrey, P.C., 2005, "The Relationship between Corporate Philanthropy and Shareholder Wealth: A Risk Management Perspective”, Academy of Management Review, 30, pp. 777-798.

Greene, W.H., 1997, Econometric Analysis, $4^{\text {th }}$ Edition, Prentice Hall, New York.

Hsiao, C., 1985, "Benefits and Limitations of Panel Data", Econometric Reviews, 4, pp. 121-174.

Johnson, O., 1966, “Corporate Philanthropy: An Analysis of Corporate Contributions", The Journal of Business, 39, pp. 489-504.

Keim, G.D., Meiners, R.E., Frey, L.W., 1980, "On the Evaluation of Corporate Contributions”, Public Choice, 35, pp. 129-136.

Levy, F.K., Shatto, G.M., 1978, “The Evaluation of Corporate Contributions”, Public Choice, 33, pp. 19-28. 
Mcguire, J., Sundgren, A., Schneeweis, T., 1988, "Corporate Social Responsibility and Firm Financial Performance", Academy of Management Journal, 31, pp. 854-872.

Mcwilliams, A., Siegel, D., 2001, “Corporate Social Responsibility: A Theory of the Firm Perspective", Academy of Management Review, 26, pp. 117-127.

Marx, J.D., 1998, "Corporate Strategic Philanthropy: Implications for Social Work”, Social Work, 43, pp. 34-41.

Modigliani, F., Miller, M., 1958, "The Cost of Capital Corporate Finance and the Theory of Investment", American Economic Review, 48, pp. 291-297.

— - _ - 1963, "Corporate Income Taxes and the Cost of Capital: A Correction", American Economic Review, 53, pp. 433-443.

Navarro, P., 1988a, "Why do Corporations Give to Charity", The Journal of Business, 61, pp. 65-93.

—_, 1988b, “The Income Elasticity of Corporate Contributions”, Quarterly Review of Economics and Business, 28, pp. 67-75.

Palazzo, G., Richter, U., 2005, "CSR Business as Usual? The Case of the Tobacco Industry”, Journal of Business Ethics, 61, pp. 387-401.

Porter, M.E., Kramer, M.R., 2002, “The Competitive Advantage of Corporate Philanthropy" Harvard Business Review, 80, pp. 56-68.

Saita, D.H., Carroll, A.B., Buchholtz, A.K., 2003, "Philanthropy as Strategy: When Corporate Charity «Begins at Home»", Business and Society, 42, pp. 169-201.

Sargeant, A., Crissman, K., 2006, "Corporate Giving in Australia: An Analysis of Motives and Barriers", Australian Journal of Social Issues, 41, pp. 477-492.

Schuler, D., Cording, M., 2006, “A Corporate Social Performance-Corporate Financial Performance Behavioural Model for Consumers", Academy of Management Review, 31, pp. 540-558.

Schwartz, R.A., 1968, "Corporate Philanthropic Contributions", The Journal of Finance, 23, pp. 479-497.

— , 1970, "The Income Elasticity of Corporate Philanthropy: Reply", The Journal of Finance, 25, pp. 153-157.

Seifert, B., Morris, S.A., Bartkus, B.R., 2003, "Comparing Big Givers and Small Givers: Financial Correlates of Corporate Philanthropy", Journal of Business Ethics, 45, pp. 195-211.

__, _ - 2004, "Having, Giving and Getting: Slack Resources, Corporate Philanthropy and Firm Financial Performance", Business and Society, 43, pp. 135-161. 
Taborda, D., Martins, A., 2011, “Corporate Philanthropy in Portugal: an Empirical Analysis", Journal of International Finance Studies, Vol. 11, n. ${ }^{\circ}$ 1, pp. 138-146.

Useem, M., 1988, "Market and Institutional Factors in Corporate Contributions”, California Management Review, 30, pp. 77-88.

Williamson, O.E., 1963, "Managerial Discretion and Business Behaviour", in Economic Organization. Firms, Markets and Policy Control, New York University Press, New York, 1986, pp. 6-31.

Wood, D.J., 1991, "Corporate Social Performance Revisited”, Academy of Management Review, 16, pp. 691-718.

Wooldridge, J. M., 2002, Econometric Analysis of a Cross Section and Panel Data, MIT Press, Cambridge.

- 2003 , Introductory Econometrics: A Modern Approach, $2^{\text {nd }}$ Edition, South-Western College Publishing, Cincinnati. 
Resumo: Este trabalho propõe-se analisar as variáveis explicativas dos donativos empresariais em Portugal. Começa por uma revisão da literatura sobre quais são essas variáveis. Posteriormente, com base numa amostra de 309 sociedades anónimas portuguesas, procede a uma estimação econométrica dessas variáveis e apresenta um cálculo da elasticidade-preço dos donativos.

Os resultados obtidos neste estudo sustentam a manutenção de um limite legal para a dedutibilidade dos donativos. Também apontam, com grande margem de segurança, para uma relação negativa e inelástica (a elasticidade-preço em valor absoluto é inferior a um). Daqui decorre que o aumento dos donativos, induzido pelo respetivo preço, é proporcionalmente inferior à perda de receita fiscal associada ao benefício fiscal concedido.

Palavras-chave: donativos, filantropa empresarial, tributação dos donativos

Tax breaks or direct transfers to the third sector? The price elasticity of corporate donations

Abstract: The purpose of this paper is to analyze the determinants of corporate philanthropy. It begins by a literature review, followed by an econometric analysis based on a sample of 309 Portuguese corporations.

We find a significant relationship between tax variables and the amount of corporate donations. Taxes are thus important factors in explaining corporate philanthropy. We also calculate the price elasticity of donations, and conclude that its value argues for limits to the tax deduction of corporate donations.

Keywords: donations, corporate philanthropy, corporate taxation

Daniel Taborda

Instituto Politécnico de Coimbra

António Martins

Faculdade de Economia da Universidade de Coimbra

BOLETIM DE CIÊNCIAS ECONÓMICAS LV (2012) 111-159 